\title{
Understanding a STEM teacher's emotions and professional identities: a three-year longitudinal case study
}

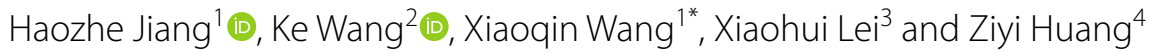

\begin{abstract}
Background: Teacher emotions are sometimes underplayed in the research field of teaching and teacher education. Also, teachers often undergo transformations in their professional identities during education reforms. However, very few studies explore the connections between teacher emotions and their professional identities against the background of education reforms, especially in Asian contexts. There is an increasing emphasis on STEM as an education reform in China and the world, and a deep understanding of STEM teacher emotions and professional identities is necessary in the fast development of STEM education. This study examined how a STEM teacher emotionally constructed her professional identities under the STEM education reform.

Methods: This is a 3-year longitudinal case study employing a narrative inquiry approach with one STEM teacher in China. Data collection included one in-depth, semi-structured interview, three conversations, personal emotional diaries, and correspondence records. A four-step data analysis was conducted.

Results: Three major themes reflecting the participant's emotional professional identities emerged, including "an interested but confused learner", "an enthusiastic but nervous explorer", and "an excited but unsatisfied mentor". In the participant's experiences as a learner, explorer, and mentor, positive and negative emotions were always intertwined. These helped construct and shape her professional identities and encouraged her to be the best STEM teacher that she could be.

Conclusion: This study provides a series of vivid and dynamic pictures of a STEM teacher's emotions and professional identities against the background of STEM education reform in China from a 3-year longitudinal perspective. It also indicates the personal, social, cultural, and contextual factors that could have strong effects on teachers' emotional experiences and the construction of professional identities. Furthermore, this study reveals that three processes (i.e., the process of education changes, the process of creating new or multiple professional identities, and the generation process of teacher emotions) could be intertwined and developed together.
\end{abstract}

Keywords: Narrative inquiry, STEM education reform, STEM teacher, Teacher emotion, Teacher professional identity

*Correspondence: xqwang@math.ecnu.edu.cn; xiaoqinwang2050@gmail. com

${ }^{1}$ College of Teacher Education, Faculty of Education, East China Normal University, Shanghai 200062, People's Republic of China

Full list of author information is available at the end of the article

\section{Introduction}

Exploring the factors contributing to professional development is an important issue in the research field of teaching and teacher education. There has been a growing interest in understanding so-called "cognitive" aspects (e.g., knowledge, skills, etc.), while teacher emotions have sometimes been underplayed (Atmaca et al., 2020; Chen, 2016; Golombek \& Doran, 2014; Uitto et al., 
2015). Particularly, although some research has focused on teacher emotions (e.g., Schutz \& Pekrun, 2007; Schutz \& Zembylas, 2009), most is set in Western educational contexts (Atmaca et al., 2020), and research in other settings is especially needed (Atmaca et al., 2020). In fact, education is an emotional effort, and emotions are at the heart of teachers' daily work, lives, and professional development (Hargreaves, 1998). Teacher emotions are important, as well as "cognitive" factors. They have a great impact on a variety of significant teaching-related outcomes (Taxer \& Gross, 2018), including teaching effect (Hagenauer et al., 2015), instructional behaviors (Becker et al., 2014), and satisfaction (Nalipay et al., 2019). Recent research has shown that many teachers experience negative emotions, leading to occupational burnout and job dissatisfaction (Atmaca et al., 2020; Bodenheimer \& Shuster, 2020; Buric et al., 2019; Chen, 2019; Torres, 2021; Zhang et al., 2020). This issue highlights an urgent need to have a deep understanding of teachers' emotional experiences and development.

Teachers experienced widely fluctuating emotions when they were involved in education reforms (Lee et al., 2013; Tsang \& Kwong, 2017). Specifically, in recent years, teachers are more likely to experience various negative emotions when they are at the period when a new reform or initiative is pushed forward (Tsang \& Kwong, 2017). This is partly because teachers often undergo the transformation of their professional identities ${ }^{1}$ to achieve congruence between the education reforms and their own professional orientations (Connelly \& Clandinin, 1999; Lee et al., 2013). Furthermore, studies have shown that teacher emotions could be regarded as integral parts of their identity formation (Yuan \& Lee, 2016) and the examination of the interaction between emotions and related teacher professional identities is of critical importance (de Costa et al., 2019). However, limited studies have explored the connections between teacher emotions and their professional identities against the background of education reforms, especially in Asian contexts (Chen, 2019).

There is an increasing emphasis on $\mathrm{STEM}^{2}$ as an education reform all over the world (El Nagdi \& Roehrig, 2020; Li et al., 2020a, 2020b; Stehle \& Peters-Burton, 2019). In Asian areas, although STEM education started late, it has been "aggressively" implemented and developed in recent years (Wahono et al., 2020, p. 3). During this booming stage in Asia, it is crucial to listen to STEM teachers'

\footnotetext{
${ }^{1}$ Teacher professional identities are the constellations of teachers' perceptions with regard to how they define themselves in their professional activities (Richardson \& Watt, 2018; van Veen \& Sleegers, 2009; Watson, 2006).

2 The meanings of STEM education are described in detail in the Context section (i.e., "Context" section).
}

voice, which has not gained sufficient attention in prior studies (Lian et al., 2021). Particularly, Asian educational culture (e.g., rote learning, teacher-directed, exam-oriented, etc.), which is different from western, potentially impacts STEM education changes and STEM teachers (Wahono et al., 2020). Therefore, more related in-depth investigations in Asian regions are necessary.

In China, the government issued the China STEM Education White Paper in 2017 and launched a reform initiative called the China STEM Education 2029 Innovation Action Plan in 2018. Since then, STEM education reform $^{3}$ has been promoted, particularly in K-12 schools. However, STEM teachers usually meet many barriers and challenges in the transformation of their professional identities, and limited well-defined experience in STEM education has been published (El Nagdi et al., 2018; Margot \& Kettler, 2019). Under the STEM education reform, it is highly possible that STEM teachers may experience different kinds of negative emotions (e.g., confusion, anxiety, frustration, upset, etc.), which is a significant factor leading to burnout and teacher attrition (Zhang et al., 2020). In this sense, a deep understanding of STEM teacher emotions and professional identities is necessary in the fast development of STEM education.

Motivated by these gaps, this current study examines how a STEM teacher, Sunjie (pseudonym), emotionally constructed her professional identities over the past 3 years, when the STEM education reform initiative was strongly promoted in China. Anchored in Sunjie's stories related to STEM education, this study focuses on and explores the emotional flux and the evolution of professional identities that a STEM teacher might experience. Particularly, a narrative inquiry approach helps not only dig into Sunjie's longitudinal experiences by presenting detailed stories, but also picture the complexities, multiple facets, and dynamics of teacher emotions and professional identities. In this sense, our narrative inquiry is necessary and important when scholars, teacher educators, administrators and other stakeholders are exploring a deep understanding of STEM teachers' non-cognitive

\footnotetext{
${ }^{3}$ An education reform comprises a series of planned education changes in various aspects (e.g., teaching methodologies, administrative processes, teacher professional development, etc.). National and local reform initiatives are essential acts or statements that are intended to implement these changes successfully. For instance, Chinese STEM education reform includes a series of planned STEM education changes in various aspects (e.g., the transformation of teaching style from teacher-centered to student-centered, the transformation of teacher-education focus from cultivating single-disciplinary teachers to cultivating transdisciplinary teachers). In order to implement these changes successfully, some reform initiatives are issued. For example, the district of the participant in this study issued a reform initiative to encouraging science teachers to develop and implement integrated STEM curricula and to develop themselves as transdisciplinary teachers.
} 
aspects. This study can contribute to the limited theoretical and practical understanding of STEM teachers' emotional experiences with the changes in professional identities. Most importantly, our study provides insights into STEM teacher development and retention against the background of a severe shortage of high-quality STEM teachers in many countries around the world.

\section{Theoretical underpinnings}

\section{Emotions and teacher emotions}

Although an absolute and widely accepted definition of emotions does not exist to date (Chen, 2020), more scholars are reaching a consensus that human emotions could be conceptualized and theorized through a sociological lens (Turner, 2009). For instance, Schutz et al. (2006) defined emotions as "socially constructed, personally enacted ways of being" (p. 344). This definition is aligned with the suggestions of social constructionism, that is, emotions are not only what occur in individual psychological activities, but also aroused by social situations and environments (Tsang \& Kwong, 2017).

Emotion is a significant aspect of understanding teachers and teaching (Sutton \& Wheatley, 2003). Research has found that teacher emotions may be evoked by diverse triggers including teachers' professional goals, education policies, student characteristics, school climate, colleagues, and socio-cultural factors (Buric \& Frenzel, 2019; Chen, 2016; Frenzel, 2014; Frenzel et al., 2009, 2018, 2020; Torres, 2021; Tsang \& Kwong, 2017). For instance, according to Frenzel et al. (2009), teachers' evaluation of the implementation of instructional goals may shape their emotional experiences. In other words, teacher emotions can be analyzed from an achievement perspective where the pursuit of success and avoidance of failure are central processes (Frenzel et al., 2009, 2020). In fact, teachers inevitably encounter failures or challenges in their teaching or professional development. This achievement perspective implies the response approaches to these challenges that teachers meet in teaching may influence their emotions. Prior studies have shown a significant relationship between teacher emotions and selfmotivation (Kazén et al., 2015; Parr et al., 2021), which is defined as people's ability to motivate themselves to perform difficult and challenging tasks (Kazén et al., 2015). Studies found that teachers with high self-motivation are more able to up-regulate positive emotions, overcome feelings of listlessness, and foster confidence and enthusiasm even when they meet challenging demands and difficulties (e.g., Kamila et al., 2014).

Moreover, teacher emotions involve dynamic interactions among personal, professional, and social environments (Chen, 2016; Tsang \& Kwong, 2017). In particular, when teachers are experiencing a stream of education changes and reforms (e.g., the twenty-first Century Skills Movement, etc.), their emotions are frequently and strongly influenced by these changes (Lee et al., 2013; Tsang \& Kwong, 2017). If teachers consider the changes or reform situation as a supportive factor in their professional needs, goals, and development, they might have positive emotions; otherwise, they might feel negative (Tsang \& Kwong, 2017). The examination of teacher emotions could help create an understanding of the achieved success and existing problems of education changes and reforms (van Veen \& Sleegers, 2009).

According to the above sociological definition (Schutz et al., 2006), the current study conceptualizes STEM teacher emotions as STEM teachers' socially constructed, personally enacted ways of being toward STEM education, STEM teaching, and STEM curriculum reforms. Based on the social construction of teacher emotions (Chen, 2016; Tsang \& Kwong, 2017), STEM teacher emotions are inevitably influenced by teachers' professional goals, policies, students, schools, colleagues, and social environments. In addition, although emotions can be categorized in various ways, two dominant and relatively independent dimensions consistently emerge in studies of emotions: positive and negative emotions (Chen, 2016). This dichotomous classification provides a framework for us to analyze STEM teacher emotions in this study.

STEM teachers' emotions could be a mirror to help create an understanding of how they react to STEM education reforms and help examine the effects of the reform implementation. However, these related studies focusing on STEM teachers' emotions are limited.

\section{Teacher professional identities}

Recently, many researchers have realized the complexities of teacher professional identities ${ }^{4}$ (Leigh, 2019; Li \& Craig, 2019; Schutz et al., 2018). The formation processes of teacher professional identities involve interactions with different social environments (El Nagdi et al., 2018; Leigh, 2019; Prabjandee, 2020). To be specific, teachers may develop new or evolved professional identities when an education reform initiative is implemented (El Nagdi \& Roehrig, 2020; Lee et al., 2013). The reasons might include that teachers may re-interpret the experiences and environments with the implications of education reforms and may transform their professional needs, goals, and positions to meet the requirements of education reforms (Vähäsantanen, 2015). Moreover, the parallel shifts in teacher

\footnotetext{
${ }^{4}$ The definition of teacher professional identities adopted in this study is presented in Footnote 1.
} 
professional identities may promote the changes in educational system (Bybee, 2010). In this sense, teacher professional identities play a significant role in education reforms.

Based on the definitions from Richardson and Watt (2018), van Veen and Sleegers (2009), and Watson (2006), this study conceptualizes STEM teacher professional identities as the constellations of STEM teachers' perceptions with regard to how they define themselves in their STEM teaching and professional development. From a sociological perspective (El Nagdi et al., 2018; Leigh, 2019; Prabjandee, 2020), STEM teacher professional identities are formed within various social and cultural contexts. As STEM education reforms are increasingly implemented around the world, teachers may develop multiple new professional identities to satisfy the requirements of new interdisciplinary ideas and approaches (El Nagdi \& Roehrig, 2020; El Nagdi et al., 2018). More importantly, STEM teachers' professional identities in the challenging surroundings of STEM education have been considered not only teachers, but also complex mixtures of learners, risk-takers, inquirers, curriculum designers, negotiators, reform implementers, researchers, and collaborators (Slavit et al., 2016).

The relationship between STEM education reform and STEM teacher identities development was once conceptualized by Bybee (2010). In the conceptualization, Bybee (2010) indicated that the process of creating new or multiple professional identities would influence and be influenced by the process of education changes and that these two processes are intertwined and developed together. Therefore, the important role of STEM teacher identities in STEM education reforms cannot be underplayed.

In China, the supply of qualified and experienced STEM teachers is inadequate (The Chinese Academy of Educational Sciences, 2017). If a teacher in China shows his/her talent and potential in STEM teaching, then he/ she will be expected to play an important role in the STEM education reforms. In fact, most STEM teachers in China inevitably experience multiple professional identities (e.g., learners, explorers, mentors, etc.). Therefore, it is essential and meaningful to examine STEM teachers' transformation and formation of professional identities and analyze the roles that STEM teachers' emotions play in it. Meanwhile, limited studies have focused on STEM teacher professional identities (El Nagdi \& Roehrig, 2020).

This current study focuses on STEM teachers' multiple professional identities, including how STEM teachers define themselves in STEM education activities and STEM curriculum reforms, and how they transform and form their new professional identities.
A conceptual framework for the relationships among STEM teacher emotions, STEM teacher professional identities, and successful STEM education changes

Many studies have indicated that the formation and transformation of teacher professional identities are fundamentally related to their emotions (Leigh, 2019; Li \& Craig, 2019; Uitto et al., 2015; Yuan \& Lee, 2016; Zembylas, 2005; Zhu, 2017; Zhu et al., 2020). The relationship between teacher emotions and professional identities is that professional identities guide teachers' emotional reactions, while teacher emotions, in turn, inform teachers' professional identities (Yuan \& Lee, 2016; Zembylas, 2005). When teachers face the requirements of education changes, they will evaluate whether their professional identities correspond to those requirements and expectations; thus, they produce various emotions (van Veen \& Sleegers, 2009). Among these emotions, positive ones usually reinforce teachers' professional identities in a context of education reforms, while negative ones usually weaken their professional identities (van Veen \& Sleegers, 2009). Considering the abovementioned relationships between teacher emotions and education changes (see "Emotions and teacher emotions" section) and the relationships between teacher professional identities and education changes (see "Teacher professional identities" section), the process of education changes, the development of teachers' professional identities, and the changes of teachers' emotions may be intertwined.

Actually, teachers' reaction to the education reforms is determined largely by their professional identities and emotions (van Veen, 2008; van Veen \& Sleegers, 2009). However, related empirical studies focusing on the understanding of the interrelationship among the three processes are needed (Nichols et al., 2017; Vähäsantanen \& Hämäläinen, 2019; van Veen \& Sleegers, 2009), especially in a context of STEM education reform.

Figure 1 shows a conceptual framework for the relationships among STEM teacher emotions, STEM teacher professional identities, and successful STEM education changes. Under the STEM education reform, successful STEM education changes may encourage STEM teachers to develop new professional identities (Bybee, 2010; El Nagdi \& Roehrig, 2020; El Nagdi et al., 2018; Lee et al., 2013; Vähäsantanen, 2015). In addition, successful education changes may arouse STEM teachers' different emotions when they respond to the requirements and expectations of the changes (Lee et al., 2013; Tsang \& Kwong, 2017). These new professional identities and emotions may influence the process of the STEM education changes (Bybee, 2010; van Veen, 2008; van Veen \& Sleegers, 2009). Particularly, professional identities corresponding to the requirements and expectations of the new changes and positive emotions may promote the 


\section{STEM Education Reform}

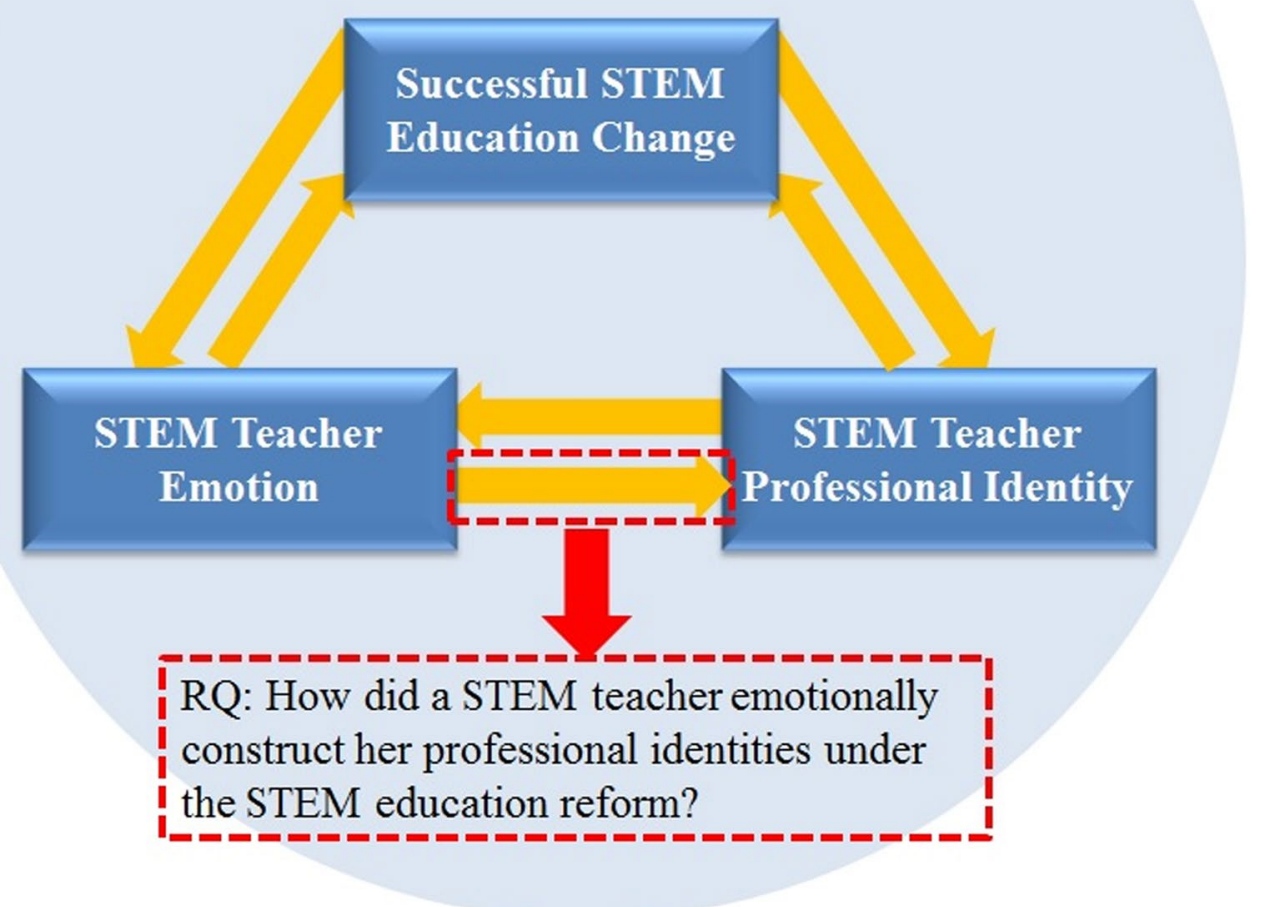

Fig. 1 A conceptual framework for the relationships among STEM teacher emotions, STEM teacher professional identities, and successful STEM education changes

process of the STEM education changes (Bybee, 2010; van Veen, 2008; van Veen \& Sleegers, 2009). A STEM teacher's emotions may fluctuate when he/she constructs a new STEM professional identity (Yuan \& Lee, 2016; Zembylas, 2005). Meanwhile, the construction of a new STEM professional identity may be shaped by the STEM teacher's emotions (van Veen \& Sleegers, 2009). The conceptual framework in this study extends Bybee's (2010) conceptualization by indicating the three intertwined and developed processes (i.e., the process of education changes, the process of creating new or multiple professional identities, and generation process of teacher emotions) under the STEM education reform.

In this current study, our goal is to examine the interactions among the three processes in the background of the STEM education reform in Mainland China. The research question is: How did a STEM teacher emotionally construct her professional identities under the STEM education reform?

\section{Research design}

\section{Research method}

Based on our research question, it may be challenging to capture the complexities, multiple facets, and dynamics of teacher emotions and professional identities by quantitative methods. Meanwhile, limited existing quantitative measures can present a comprehensive picture of teacher professional identities (Hanna et al., 2020). Instead, telling the narratives is an efficient way for teachers to explain their actions, make sense of their relationships with environments, recollect what they experienced, reflect on their pasts, recall and express the wave of emotions, and construct and reconstruct their professional identities (Connelly \& Clandinin, 1999; Yuan \& Lee, 
2016). Therefore, narrative inquiry has been regarded as a suitable and useful method of understanding and characterizing teacher emotions and professional identities (Leigh, 2019; Li \& Craig, 2019; Yuan \& Lee, 2016; Zembylas, 2005; Zhu et al., 2020). It is worth noting that although some previous studies employed a narrative inquiry approach to explore teacher emotions or professional identities (Hong \& Cross Francis, 2020), few studies have discussed the relationship between them from a longitudinal view (Li \& Craig, 2019). Moreover, narrative inquiries into STEM teachers' emotions or professional identities are rare.

This study is part of a larger collaborative project among a Tier-1 Research Normal University, local institutions of education, and schools in some provinces or municipalities of China, aiming to promote STEM teachers' professional development. By employing a narrative inquiry method, this study looks into the storied experience of a Chinese STEM teacher, Sunjie, and reports her 3 -year longitudinal trajectories of emotions and professional identities.

Sunjie's experience is explored in a metaphorical three-dimensional narrative inquiry space, namely, temporality, interaction, and place (Clandinin \& Connelly, 2000). In terms of temporality, Sunjie's past and present experiences related to STEM education are traced and her future professional goals and ideals are explored. As for interaction and place, the background of STEM education in China, Sunjie's school landscape, Sunjie's exchange study in the USA, Sunjie's interaction with other people and contextual elements (e.g., school and social environments), and Sunjie's inner emotional world are examined.

Focusing on one participant's experience may help go deep into her inner thoughts to picture the complexities, multiple facets, and dynamics of teacher emotions and professional identities as specifically as possible. This may further enable us to better achieve our research goal. During the research, we laid down our authority to interpret Sunjie's stories. We also engaged ourselves into the co-composition process of telling and re-telling, living and re-living (Clandinin \& Connelly, 2000). Methodologically speaking, researchers and readers are all co-composers of Sunjie's narratives, whose resonations are important in a narrative inquiry approach (Clandinin \& Connelly, 2000; Craig, 2019).

\section{Context}

STEM education has various meanings internationally (English, 2016; Hallström \& Schönborn, 2019; Kelley \& Knowles, 2016; Leung, 2020; Li, 2020; Li \& Anderson, 2020; Li et al., 2019, 2020a; Yata et al., 2020). STEM education can be viewed as individual disciplinary-based education separately in science, technology, engineering and mathematics ( $\mathrm{Li}, 2018$; $\mathrm{Li}$ et al., 2020a). Meanwhile, with the appearance of the definition of STEM education in the US documents, many researchers pay more attention to interdisciplinary or cross-disciplinary combinations of the individual STEM disciplines in the past decade (e.g., English, 2016). The China STEM Education White Paper also states that STEM education is a coherent group of cross-disciplinary curricula (The Chinese Academy of Educational Sciences, 2017). This statement shows the emphasis on STEM integration in China.

In China, in June 2016, the Ministry of Education published The 13th Five-year Plan of Education Informatization. STEM education was first advocated in K-12 schools. In February 2017, the new standards of the primary school science curriculum introduced STEM education as a form of curricular organization. This definition of STEM education focuses on the integration of science, technology, engineering, and mathematics and pays special attention to project-based learning and problem solving (Ministry of Education of the People's Republic of China, 2017). It was the first time that STEM education was introduced in official curriculum standards. In June 2017, The Chinese Academy of Educational Sciences published the China STEM Education White Paper, aiming to promote the design of STEM education policies and the implementation of STEM education. In May 2018, the Chinese government launched the China STEM Education 2029 Innovation Action Plan. This is regarded as the official start of STEM education and curriculum reform in China. Since then, the idea of STEM education has been gradually incorporated into more curriculum standards, and some teachers have been trained to be STEM teachers.

Under the STEM curriculum reform, teachers want to change their traditional teaching modes and develop their students' comprehensive skills (Peng \& Zhu, 2020). First, STEM teachers in China think that students can become real protagonists of the classroom. Specifically, students will experience the exploration by hand, and work together to complete STEM tasks in STEM teaching. This is completely different from traditional teaching modes in which students only accept teachers' instruction. Second, STEM teachers in China think that science, technology, engineering, and mathematics can be integrated to form a comprehensive curriculum system in which students can integrate fragmented knowledge into a unified whole. This will help students learn to use interrelated knowledge to solve specific realistic problems and understand the real world from a systematic perspective. In this way, students' comprehensive skills (e.g., twenty-first century skills, practical ability, innovative 
ability, etc.) will be promoted, while traditional education focuses more on students' exam-taking ability.

Many STEM teachers reported that they suffered high pressure or other negative emotions under these reform initiatives (Zhang \& Sun, 2018). STEM teachers are encountering various difficulties and challenges in meeting the requirements of this reform when they play roles as school-based STEM curriculum developers, active implementers of innovative STEM teaching practices, and facilitators of students' STEM learning (Dong et al., 2020). Put simply, it has been increasingly recognized that the job of a STEM teacher in China is challenging.

\section{Participant}

The current study adopts a purposive sampling technique that is typically used in qualitative studies (Etikan et al., 2016). It involves deliberate identification and selection of individuals that are well-informed in a certain field or possess particular qualities (Etikan et al., 2016). To facilitate a focus on STEM teaching experience, we delivered invitations to several available experienced STEM teachers. We briefly investigated the teachers' background and characteristics after excluding those who were unwilling to participate. Finally, we selected one participant with the richest information.

The participant, Sunjie, is an experienced STEM teacher in Shenzhen city. She works in a public school, which usually supports innovative curriculum and teaching reforms to cultivate students' scientific thought, humanistic spirit, and comprehensive competitiveness. Sunjie became a science teacher in 1996 after graduating from a normal university. From September 2016 to March 2017, Sunjie studied as an exchange teacher for half a year in Austin, Texas, USA. This was the first time that she had formally learned STEM education. In March 2017, she returned to China and began trying to implement integrated STEM teaching. After one and a half years of exploration, in September 2018, with the goal of better promoting STEM education reform in her district, Sunjie built a STEM teaching studio. She became a mentor who voluntarily guided young teachers in implementing integrated STEM teaching. In Sunjie's words, she is a witness, participant, and implementer of the whole STEM education reform in China.

Sunjie claims that STEM education is an ideal education model because it not only integrates interdisciplinary knowledge from science, technology, engineering, and mathematics, but also guides students in posing and solving realistic problems, usually by project-based learning, and aims to improve students' twenty-first skills. Sunjie thinks that STEM education has become an important way to cultivate innovative talents to meet the demands of the future society. She said that her ideas on STEM education were partly from what she studied in Austin, Texas, USA. More importantly, when she explored integrated STEM teaching in China, she carefully considered how to combine American ideas with Chinese policies and school realities. In addition, with the growing interest in STEM education in China in the past several years, especially after May 2018, Sunjie learned some Chinese practice cases and experience of STEM education. She emphasized that this kind of learning contributed to the development of her ideas on STEM education. In short, her ideas on STEM education were from what she learned in China and the US, as well as Chinese education policies and school realities.

\section{Data sources}

This current study collected multiple data sources of field texts. The first data source was made up of one in-depth, semi-structured interview (conducted in September 2019) and three conversations (conducted, respectively, in August 2017, 2018, and 2019). The interview lasted $120 \mathrm{~min}$ and each conversation ranged from 50 to $70 \mathrm{~min}$. They were all audio-recorded and then transcribed verbatim. In the interview, Sunjie was invited to review her overall 3-year experiences related to STEM education, her emotions at different stages, her perception of the formations and transformations of her professional identities, and her comments about Chinese STEM education reforms (for sample interview questions, see the appendix). Each conversation focused on Sunjie's experiences during that year (e.g., her interactions with different people, her response to STEM education reform measures, her implementation of integrated STEM teaching, etc.), various emotions resulting from these experiences, and reflections about her professional identities. ${ }^{5}$ Compared to an overview of 3-year experiences in the interview, more details and subtle changes regarding Sunjie's emotions and inner thoughts were recorded in the conversations. In addition, Sunjie introduced her biographies many times in the interview and conversations.

\footnotetext{
${ }^{5}$ Conversations are less formal than interviews. They take place in a less intense environment than interviews. Participants are likely to feel more relaxed and comfortable in the conversations. Structured or semi-structured outlines or protocols are not necessary in the conversations. Conversations are used by many researchers in narrative inquiry (e.g., Li \& Craig, 2019; Zhu et al., 2020). They help improve the relationship between researchers and participants, which is placed emphasis on in a narrative inquiry approach (Clandinin \& Connelly, 2000; Macqueen \& Patterson, 2020; Yuan \& Lee, 2016). We told our participant the main focuses before each conversation. When Sunjie's sharing deviated from the focuses, we gave her appropriate polite reminders or questions to bring the conversations back.
} 


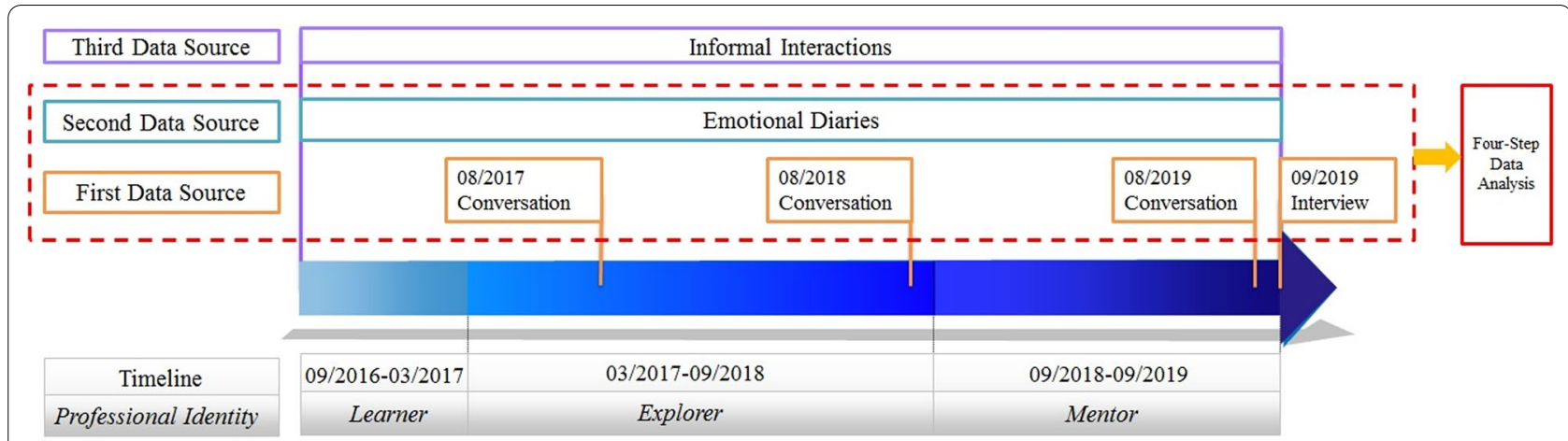

Fig. 2 An overview about the timeline of data collection and Sunjie's professional identities

Particularly, Sunjie had a habit of writing "emotional diaries" ${ }^{\prime \prime}$ (Zembylas, 2005). In the diaries, Sunjie recorded important activities, emotions, and reflections about STEM education. At the end of the research, Sunjie voluntarily shared 30 of the most representative diary entries. She agrees that these 30 diaries entries reflect her emotional experiences and inner thoughts at different stages. The second data source included these emotional diaries, which were used to obtain a whole picture of Sunjie's experiences.

During the process of data collection over the 3 years, two authors corresponded with Sunjie. Phone calls, online conversations, informal discussions, and meetings (e.g., a short chat after class, etc.) were also recorded and archived, which constituted the third data source.

An overview about the timeline of data collection and Sunjie's professional identities is presented in Fig. 2.

\section{Data analysis}

Data from the first and second sources (i.e., interview and conversation transcripts, and emotional diaries) were coded and analyzed. To be specific, the data analysis process consisted of four steps. First, to build the "plot" of the story (Polkinghorne, 1995, p. 6), the data were sorted chronologically. Second, the data were carefully reviewed, various emotions were categorized and coded, and the way these emotions related to different professional identities was noted and identified. As a result, three major themes reflecting Sunjie's emotional professional identities emerged: "an interested but confused learner", "an enthusiastic but nervous explorer", and "an excited but

\footnotetext{
${ }^{6}$ In Mainland China, some teachers have the habits of writing emotional/ teaching/pedagogical/reflection/working diaries. Some schools also require teachers (especially novice teachers) to develop such habits, which are considered to have the potential to promote teacher professional development. Sunjie was recommended to write diaries by her school before she went to the USA to promote her reflection as an exchange teacher. Our researchers did not carry out any intervention when she wrote the diaries.
}

unsatisfied mentor". Third, the themes were doublechecked in depth by rereading the original data. Finally, "mini-stories" (Clandinin \& Connelly, 2000) including specific time, space, and characters were composed. Particularly, in the process of composing mini-stories, the personal, contextual, and social meanings related to the identified themes were deconstructed, constructed, and reconstructed (Clandinin \& Connelly, 2000). Then, the storyline of Sunjie's narratives was developed and further knitted into "story constellations" (Craig, 2007). The story constellations can show the emotional process of identity formation and transformation.

According to Yuan and Lee (2016), data from the third source may not be subjected to formal analysis. However, by reading these informal interactions, researchers benefit from generating insights for the understanding and interpretation of the participants' emotional experiences and construction of professional identities. In this current study, these data helped us understand the first and second data sources better and further confirmed the conclusions. Moreover, such kinds of informal interactions helped to build a very good researcher-participant relationship, which has been considered a significant aspect of narrative inquiry (Macqueen \& Patterson, 2020). Based on this relationship, Sunjie would like to share her stories sincerely and spontaneously.

\section{Trustworthiness}

The narrative inquiry method relies on criteria and seeks what is true for now (Bruner, 1987) rather than validity, reliability, and generalizability (Connelly \& Clandinin, 1990). In other words, narrative inquiry aims to convey the truth as the participants see it (Bruner, 1987) from the perspective of the researchers and the experiences of the readers (Craig, 2019). In this current study, on the one hand, all the identified themes and findings were triangulated (Denzin, 1989) by comparing the data from the first and second sources. On the other hand, two authors 
analyzed the data independently and then all the authors collaborated to cross-check the meanings to enhance the trustworthiness of the findings. Most importantly, we shared the preliminary conclusions with Sunjie and asked for her comments on the data interpretations. This action helped confirm that what she saw and experienced was the same as what we understood.

\section{Findings}

In this section, three narrative threads from Sunjie's stories at different stages are shared. Over the 3 years, there were many details about Sunjie's emotional change and identity construction. The following is a brief report of the research findings.

\section{Thread 1: an interested but confused learner}

Sunjie's story with STEM education started in September 2016, when she attended academic lectures as an exchange teacher in Austin, Texas, USA. She showed a keen interest in the idea of STEM education, "I was very interested, or even excited, when I first learned STEM education in Austin". As for the reasons, she explained:

I consider that the ideas of STEM education have much in common with my own education philosophy. Looking back on my 20-year science teaching experiences, I always unconsciously introduced some technology, engineering, and mathematics knowledge in class. I think [they are] very meaningful and valuable. [This is] because, on the one hand, I want to broaden my students' views; on the other hand, I think this knowledge is inevitably needed when solving real science problems in our lives.

Sunjie emphasized that she truly believed that science cannot and should not be taught in isolation and that students need to connect science with more disciplines when they encounter real-world problems. Furthermore, Sunjie regarded STEM education as an interdisciplinary or cross-disciplinary curricular innovation that integrates science, technology, engineering, and mathematics. She thought that STEM education often focuses on projectbased learning, inquiry-based learning, and solving realworld problems. These features are especially essential for teachers to help students become active learners and develop their creativity. ${ }^{7}$ In fact, Sunjie mentioned many times that she was deeply attracted by the educational values of STEM education, which further increased her interest in STEM education.

\footnotetext{
${ }^{7}$ We found that Sunjie's understanding of STEM education was aligned with the definition of STEM education in Chinese STEM education policies (e.g., Ministry of Education of the People's Republic of China, 2017; the Chinese Academy of Educational Sciences, 2017).
}

Sunjie's interest stemmed from her personal positive beliefs in STEM education (e.g., her recognition of the ideas and values of STEM education). This interest drove her to study hard. As Sunjie recalled, she went to the libraries to search for related references, carefully learned many developed STEM curricula, and asked her teacher friends in Austin for advice on the implementation of integrated STEM teaching. ${ }^{8}$ Also, she emphasized that it is not easy to be an effective learner of STEM education. She had to mull over and investigate many details to better learn a new, promising, interesting, and valuable pedagogy. This process sometimes made her tired. Meanwhile, Sunjie mentioned that all these were what an interested and hardworking learner may experience. When she effectively learned some ideas of STEM education, she felt more confident of her professional identity as an effective learner. To some degree, this learning process helped develop her professional identity as a learner.

After one semester spent studying STEM education, Sunjie said that, in her diary, she had set a higher professional goal: "to be one of the first STEM teachers":

The more I learn about STEM education, the more I become interested in it... I am so interested in it, and I want to put it into practice... The Ministry of Education has published an initiative to advocate STEM education... Since I am very interested in it and [it] is advocated, I hope I can try integrated STEM teaching in Chinese classrooms... I am eager to be one of the first STEM teachers in my hometown.

This statement indicated that Sunjie generated the preliminary thought of transforming from a learner to a practitioner due to the increase of her interest in STEM education and support of reform policy.

Although Sunjie decided to try integrating STEM teaching as a practitioner, she had a clear understanding of the contradictory factors in STEM education changes in China at that time. As Sunjie said, "STEM education was mentioned in the national and local government documents, but [it] had hardly been implemented [in my hometown].... On the one hand, STEM education was

\footnotetext{
${ }^{8}$ Based on our understanding of Sunjie's words, integrated STEM teaching referred to the classroom teaching activities in which science, technology, engineering, and mathematics were integrated, while STEM education referred to the broader education activities (e.g., classroom teaching activities, out-of-class learning activities, etc.) in which science, technology, engineering, and mathematics were introduced. Integrated STEM teaching was included in STEM education. When it comes to STEM education, Sunjie may want to focus on its educational values, current situation, development challenges, potentials, or other macro aspects. However, when it comes to integrated STEM teaching, Sunjie may want to focus on micro specific teaching activities.
} 
advocated nationally and locally. On the other hand, integrated STEM teaching was rarely implemented in Sunjie's hometown. Sunjie explicitly knew that there was a mismatch between policy advocacy and school reality, and the real effect of STEM education in practice in China had not been studied. Moreover, the features of STEM education (e.g., focusing on project-based learning and inquiry-based learning and solving real-world problems) are not in line with Chinese traditional educational culture and the teacher-centered classroom culture. These two mismatches sometimes made Sunjie feel confused and unsure about the effectiveness of what she wanted to do in the Chinese context:

Chinese traditional [classroom culture] is teachercentered while STEM education advocates studentcentered [classroom culture]... Could Chinese students also benefit from it like western students ... [since] the real impact of ... this [curricular innovation] ... had never been examined? ... [I am] confused about [its] effectiveness in China...

To be clear, Sunjie expressed that, as for the effectiveness of STEM education, she felt confused and uncertain rather than worried at that time. There were two reasons for this. First, Sunjie emphasized that she had unconsciously introduced some technology, engineering, and mathematics knowledge in her science class over the last 20 years. She thought that students could accept STEM education based on her experience. Second, despite the existence of challenges delaying the implementation of STEM education ideas, Sunjie believed that her understanding of STEM education aligned with many education policies in China. China is building itself into an innovative country, and many policies are issued to help develop students' creativity, including policies on STEM education changes. Because of this, Sunjie believed that the exam-driven educational culture would change in the future (although it would take time) and that STEM education could be fitted into Chinese classrooms.

During her time in Austin, Sunjie perceived herself as a learner and prospective STEM teacher. As Sunjie wrote, she was attracted by the idea of STEM education and was interested in the theory and practice of it; meanwhile, from time to time, she felt confused about its effectiveness in Chinese classrooms. These emotions (i.e., interest, confusion, etc.) were influenced by Sunjie's personal beliefs (related to her prior teaching experience), education policies, and educational realities in China. Sunjie further said that the more interested and confused she was, the more she wanted to understand STEM education in depth, and the more she wanted to implement integrated STEM teaching. This further motivated her to be an active explorer soon after returning home. ${ }^{9}$

\section{Thread 2: an enthusiastic but nervous explorer Preparation and implementation of first integrated STEM teaching: principal's and colleagues' attitudes and students' performance as significant external factors of emotion}

With a strong desire to implement integrated STEM teaching, Sunjie nervously submitted a teaching proposal as soon as she returned to her hometown. It is worth noting that although some initiatives were put forward to advocate STEM education, most school principals did not follow them at that time. Luckily, Sunjie's principal supported her. Sunjie recalled how she felt when she became an explorer:

I was so happy and excited that I had the opportunity to explore what I was really interested in and to be among the first to implement the STEM curriculum reform ideas... However, my principal and colleagues expressed their anxiety about my teaching effect... They would come to observe my integrated STEM teaching. This made me feel really nervous and stressed. I thought I could not disappoint them.

Her principal's and colleagues' attitudes greatly influenced Sunjie's emotions. As Sunjie described it, anticipation, excitement, enthusiasm, and nervousness were interwoven. She hoped to present an impressive lesson. She expected that her principal, colleagues, and students would enjoy integrated STEM teaching and, thus, actively respond to the STEM education initiatives. Furthermore, she was not very confident in her integrated STEM teaching and was worried that she might fail to meet her principal's and colleagues' expectations. This emotional state existed throughout the entire process of preparing and implementing integrated STEM teaching. She said that although she indefatigably and enthusiastically perfected her instructional design repeatedly, she was still worried that the design was not good enough. This situation made her very nervous. She described her nervousness with the details that she tossed and turned in bed the night before the implementation. Most importantly, Sunjie's enthusiasm for STEM education never waned. She shared some exciting things with us: "One of my colleagues praised [me] that my design was better and better... [And thus,] I felt a little bit more confident and a taste of accomplishment... The positive comments also

\footnotetext{
${ }^{9}$ Actually, Sunjie had been interested and confused throughout the three years. However, these two kinds of emotions are not dominant in the next two threads. They were sometimes replaced by stronger emotions (e.g., enthusiasm, excitement, etc.).
} 
made me more enthusiastic about what I was interested in."

However, the implementation of her teaching was not going very well. Perhaps her students were bound by the traditional teacher-led classroom experiences. During the integrated STEM teaching, the students did not perform as expected. First, they did not know how to collaborate with others in project-based learning. Although Sunjie divided the class into several groups and asked students to work in groups to solve a problem, the students did not actively communicate and work on the problem within their groups. Students regarded the STEM problem as simply a traditional classroom exercise and solved the problem independently. Sunjie frequently asked them to communicate with peers, but most of the students kept silent. Second, students thought that it was difficult to understand and combine knowledge and ideas from different disciplines to solve a STEM problem. For instance, Sunjie provided them with a problem related to sewage treatment. Students understood the constituents of domestic sewage but did not understand the sewage disposal technology and did not know how to design sewage treatment tanks based on that technology. Third, students were unwilling to interact with Sunjie. They were more willing to accept Sunjie's instruction instead of sharing their thoughts and ideas with Sunjie. Fourth, when students were asked to solve open-ended problems or design something new, they were at a loss about what they had to do. This implied that students were bound by solving problems with standard answers. As a result, students' response to teaching was not so good. Meanwhile, based on students' responses, some colleagues expressed doubt about this teaching style; some teachers even questioned the STEM education reform initiatives.

This discouraged Sunjie. As she said, students' performance and colleagues' doubts made her extremely sad and depressed in the next week.

Significantly, her principal's and colleagues' attitudes towards Sunjie's teaching and students' performance were important external influential factors affecting her emotions when Sunjie prepared and implemented her first integrated STEM teaching. Before her teaching, Sunjie knew that she would be observed and assessed. She hoped that her principal and colleague would have positive attitudes toward her STEM teaching and give positive feedback. This produced huge pressure on her and made her feel nervous. Meanwhile, some positive and kind comments from her colleagues made her feel relieved and enthusiastic. Finally, her students did not perform as well as she expected during her first teaching. She found that her principal's and colleagues' attitudes toward her teaching were not as positive as she had expected. This made her sad and discouraged.

\section{Making the decision after an intense inner struggle:} self-motivation as a significant internal factor of emotion

Failure is essential to the success of the implementation of STEM education. Sunjie did not give up. After watching the teaching videos and reflecting on the problems in her teaching implementation, she told herself that she had to pull herself together and continually explored how to implement integrated STEM teaching in Chinese classrooms.

Sunjie decided to go on after an intense inner struggle. She expected to show the educational values of integrated STEM teaching and actively changed the exam-centered and teacher-led teaching style. Meanwhile, she was worried that she did not have the strong abilities to change her students and classrooms. Also, she had anxiety that her students would not accept and embrace the changes. Sunjie said that she was very perplexed, nervous, and worried at that time. However, although Sunjie had internal doubts, she motivated herself to make more efforts to be an effective STEM teacher.

More importantly, Sunjie knew that there would be many challenges in the future. However, she motivated herself to continue implementing STEM education. She tried her best to make a difference, deviating from the old style of exam-centered and teacher-led teaching, and was undeterred by future challenges. This self-motivation, stemming from her strong beliefs in STEM education, helped her adjust her emotions to keep exploring integrated STEM teaching after the failure.

Particularly, this intense inner struggle helped Sunjie not only understand the opportunities and challenges that a STEM teacher may face, but also think clearly about her professional goals and identities. As Sunjie explained, she figured out the in-depth meaning of the word "explorer". She said that an explorer was bound to encounter many difficulties and struggles. As an explorer, she was travelling to an ill-defined practice field in order to know more about it. If she gave up when she encountered troubles, she could never bring anything new to the small world around her. She considered that an explorer is a courageous person who may experience anxiety and upset in the process of discovery and experience excitement after making a discovery.

\section{Overcoming the challenges: internal and external influential factors mixed}

The difficulties of exploring and implementing integrated STEM teaching produced negative emotions in Sunjie. After deciding to continue, Sunjie made efforts to overcome negative emotions in her daily work. Particularly, the education policies regarding STEM education, as a critical external factor, played an important role in eliminating Sunjie's negative emotions during this process. In 
June 2017, the China STEM Education White Paper was published, and some STEM education and curriculum reform initiatives were issued. Although many schools did not respond to it immediately, Sunjie more firmly believed that what she did was valuable and meaningful. Meanwhile, these policies further increased her enthusiasm for STEM education.

For nearly one and a half years, Sunjie diligently and enthusiastically explored how to implement integrated STEM teaching once a month. ${ }^{10}$ Sunjie asked for advice from instructional experts from the university, investigated her students' learning needs, informed her students with more knowledge about transdisciplinary themes, provided students with more effective guidance in cooperative or project-based learning, and thought about how to enhance students' interdisciplinary synthesis ability. ${ }^{11}$ She hoped her students liked and benefited from her teaching. All this showed her enthusiasm for STEM education. These specific strategies helped Sunjie move her integrated STEM teaching forward, and further internally kept her enthusiastic. Meanwhile, Sunjie mentioned that an enthusiastic explorer was very likely to have a sense of responsibility and would try her best to use various available strategies to overcome the difficulties effectively. Sunjie admitted that enthusiasm helped her develop her professional identity as an explorer. She also

\footnotetext{
${ }^{10}$ Sunjie developed some semester-long projects for her monthly integrated STEM teaching. These projects could be divided into several subprojects or subtasks. In Sunjie's monthly classrooms, the integrated STEM teaching was usually incorporated in project-based learning, and one subproject was focused on in the integrated STEM teaching. For example, the day before Sunjie's teaching implementation, each student was given a worksheet. In the worksheet, Sunjie asked students to preview some background information that may be used on the following day. At the beginning of her classrooms, Sunjie introduced the subprojects. Subsequently, students were divided into groups/teams and guided to solve related tasks cooperatively. At the end of her classrooms, Sunjie helped analyze the problems that students encountered in their inquiry. She also guided students to present a knowledge network that related different knowledge and to identify the connections between different subprojects/subtasks. This process improved students' understanding of relevant knowledge required by the curriculum standards.
}

${ }^{11}$ In Sunjie's first several teaching implementations, she found it was difficult for students to connect knowledge from different subjects. Some students failed to grasp knowledge required by the curriculum standards when they enjoyed the pleasure of inquiries in the project-based learning. This provoked criticism from her colleagues. Interdisciplinarity is an important characteristic of integrated STEM teaching. Sunjie stated that she was very upset and anxious about the problem. She asked her colleagues and instructional experts for suggestions, investigated the learning methods of students who performed well in her class, and explored different potential ways to enhance students' abilities of interdisciplinary synthesis. Finally, Sunjie found it was useful to picture a knowledge network together with students. After each class, Sunjie guided students to construct a knowledge network that could be used to present what students learned in the project-based learning (in their project-based learning, students usually had many opportunities to learn interdisciplinary knowledge). This process also helped students summarize what they learned and understand the connections or integration of different knowledge. became more enthusiastic about what she was exploring after overcoming some difficulties as an explorer.

Undoubtedly, the exploration of integrated STEM teaching was very challenging. Sunjie described the exploration process briefly and her mixed emotions:

For each integrated STEM teaching, I revised and perfected the instructional designs, collected students'feedback, and reflected and analyzed teaching effects many times... Although [I] put a lot of effort, I still experienced a lot of unsuccessful teaching ... I experienced the emotions of enthusiasm, nervousness, anticipation, and joy repeatedly almost every month.

Particularly, Sunjie repeated that it was challenging to shape a courageous explorer. She claimed that learning from mistakes, failures, and setbacks could help her become a better explorer.

What supported her in facing the challenges (e.g., colleagues' misunderstandings, unsatisfactory teaching effect, inactive students, etc.)? Sunjie emphasized the importance of enthusiasm for STEM education and regarded it as an inner fire that kept her going:

Enthusiasm for STEM education was [the] most
important [support]... It gave me the motivation to
keep active in doing what I loved and wanted to...
I think that the process of being a STEM teacher
requires faithful youthful enthusiasm and down-to-
earth efforts. This process was a persistent climbing.
Without enthusiasm, it was difficult to overcome
many obstacles.

Sunjie admitted that she had suffered much external pressure in some periods (e.g., she worried that her students would not do as well in the final exams as they had done before because of her incapacity to implement integrated STEM teaching, she worried that her colleagues would not understand and accept her teaching, etc.). However, Sunjie told us that she gradually learned an active way to understand and regulate negative emotions. She tried to stay positive when negative emotions emerged. For instance, she gradually treated integrated STEM teaching with a common expectation, which helped reduce the nervous tension. In addition, she learned to consider her unsuccessful teaching as an opportunity to learn instead of something that made her sad. These strategies of emotion regulation, as important internal factors, helped Sunjie stay positive. Meanwhile, Sunjie's self-motivation influenced her emotions. Sunjie realized that motivation usually comes from pressure. She thought that her nervousness and anxiety made her work hard. In addition, working toward her dreams relieved her nervousness and anxiety. 
During this period, mixed internal and external factors interacted and influenced Sunjie's emotions. She encountered many external challenges and pressures (e.g., colleagues' misunderstanding, unsatisfactory teaching effect, students' inactiveness, students' poor test scores, her school's wavering support, etc.), which made her nervous and a little worried. Meanwhile, some internal factors (e.g., self-motivation, emotion regulation strategies, specific strategies to move teaching forward, etc.) helped her stay positive and enthusiastic. In addition, education policies regarding STEM education played an important role in eliminating Sunjie's negative emotions. The critical external factor of education policies cannot be ignored as a factor in the change of Sunjie's emotions.

\section{Repositioned as a model STEM teacher: STEM curriculum reforms as external triggers of emotion}

In September 2018, some school STEM curriculum initiatives were issued in Sunjie's district, and many schools began strongly promoting STEM education. As Sunjie was one of the few experienced teachers in the field of integrated STEM teaching, many mathematics and science teachers in her district came to observe her teaching and communicated with her about STEM education. This interaction between Sunjie and other teachers repositioned her as a model STEM teacher in her district. Although this situation made Sunjie more nervous, her enthusiasm for STEM education was further kindled when many more teachers became interested in integrated STEM teaching. For instance, some of the interested teachers were very appreciative of the shift from a teacher-led classroom to a student-centered classroom. They believed that Sunjie's attempts were aligned with what the new curriculum changes encouraged. In addition, some teachers agreed with Sunjie's teaching ideas and considered it meaningful to integrate science with more disciplines. Many of these teachers told Sunjie that they wanted to follow her model to try integrated STEM teaching. This made Sunjie very excited.

Actually, the external triggers of these school STEM curriculum changes influenced Sunjie's emotions. Sunjie was repositioned as a model STEM teacher in her district. She received many positive comments from her colleagues. Moreover, the alignment between Sunjie's attempts and what the education changes encouraged was recognized. This externally strengthened Sunjie's positive emotions.

\section{A brief summary of Sunjie's experience as an explorer}

With regard to Sunjie's experience as an explorer, enthusiasm and nervousness were her two dominant emotions. On the one hand, she was nervous and worried about her teaching effects and her colleagues' and students' attitudes toward STEM education. This nervousness and worry made her feel insecure about her professional identity. "Could my integrated STEM teaching be accepted? Could I be an accepted and recognized STEM teacher?" Sunjie asked herself repeatedly. Meanwhile, she tried her best to learn how to regulate emotions and relieve stress. On the other hand, her enthusiasm for STEM education motivated her to be a better STEM teacher and keep going.

Both external and internal factors influenced Sunjie's emotions. For instance, Sunjie regarded STEM education policies as a support for her professional goal and identity and sources of her positive emotions. In addition, comments from colleagues and students, students' performance, and social environments (e.g., the Chinese traditional exam-centered culture) were powerful external factors influencing Sunjie's mixed emotions. When meeting challenges, Sunjie can use some internal emotion regulation strategies to stay positive. The irreplaceable internal factor of self-motivation was a powerful source of her enthusiasm. Both external and internal factors intertwined to impact her mixed emotions. These emotions further played an important role in shaping Sunjie's professional identity as an explorer in the background of STEM curriculum reforms.

Sunjie gradually enhanced her understanding of the professional identity as an explorer. At first, she defined herself as an explorer when she had the opportunities to implement integrated STEM teaching. However, she may not know the in-depth meaning of an explorer clearly. After experiencing a failure of integrated STEM teaching and an intense inner struggle, she understood that an explorer must encounter many difficulties and struggles. When she faced more difficulties and struggles, she realized that an explorer should learn from mistakes, failures, and setbacks. Also, she realized that the process of overcoming difficulties may help her become a better explorer. With the improvement of the understanding of her professional identity as an explorer, Sunjie regulated her emotions when facing failure and challenges. She did not feel as intense and anxious as she felt during her first failed teaching. She took her unsuccessful teaching as an opportunity to learn rather than thought it as the origin of her sadness. All these further showed that the formation and development of professional identities impacted teacher emotions. Moreover, Sunjie admitted that enthusiasm helped her cultivate her professional identity as an explorer, and when her professional identity was developed (e.g., she overcame some difficulties), she became more enthusiastic about what she was exploring. This indicated the two-direction interactions between her emotions and professional identities. 


\section{Thread 3: an excited but unsatisfied mentor}

In September 2018, the education department in Sunjie's district issued another local initiative to promote STEM education and curriculum changes. This initiative included a more detailed plan encouraging science teachers to develop and implement integrated STEM curricula in their schools. Against the background of this initiative, Sunjie built a STEM teaching studio ${ }^{12}$ and became a mentor who voluntarily trained young teachers to learn and implement integrated STEM teaching. As for the original intention to build the studio, Sunjie explained:

So many stories with STEM education happened to me. To some degree, [my stories] heavily stimulate my enthusiasm for STEM education... With this strong enthusiasm, I always thought I could do more to better promote ... the STEM education in my district... Since the new initiative encouraged young teachers to try integrated STEM teaching, many of them wanted to follow [the initiative]... Thus, it is a very good opportunity for me to contribute to the reform.

This statement revealed that Sunjie's strong enthusiasm was a driving force for the transformation of her professional identities between explorer and mentor. As a mentor, Sunjie shared her STEM teaching experiences with her mentees. During her mentees' implementation of integrated STEM teaching, she provided comments about their implementations to help improve their teaching abilities. All mentees designed the lesson plans, discussed the solutions to problems encountered in their designs and implementations, observed teaching videos, and analyzed students' feedback together with Sunjie. Sunjie told us that she was very excited to be a mentor in the studio: "Nothing was more exciting than implementing integrated STEM teaching with a group of enthusiastic young explorers". Meanwhile, this excitement was related to her mentees' performance, school leaders' and instructional experts' recognition and encouragement, and teachers' attitudes toward STEM education reform. As Sunjie said,

We implemented many successful STEM teaching together after hard work together. I witnessed my mentees' progress in integrated STEM teaching... Many leaders, experts, and researchers recognized our teaching implementation and gave us different

\footnotetext{
${ }^{12}$ A STEM teaching studio is a learning community that aims to help its members develop their profession in STEM teaching. One expert teacher is the mentor of this community. All members from various schools are young teachers who are interested in implementing integrated STEM teaching. Teaching studios are common in Mainland China (Wang et al., 2017; Wang et al., 2018).
}

kinds of encouragement and support... Meanwhile, there were more and more like-minded young teachers actively participating in the implementation of the reform around us... [All these things] made me very excited.

While excited by the growing influence of integrated STEM teaching in her district, she still felt unsatisfied because of some resistance to the reform and the gap between ideal and reality in her mentees and teaching. Sunjie wrote about her un-satisfaction in her diary:

\section{Although some initiatives about STEM education have been issued... [by the local education depart- ment], some school principals and leaders still do not respond to it actively. This situation created blocks for some young teachers who are interested in integrated STEM teaching... I know that it is com- mon that some people may be cautious or conserv- ative about new initiatives. However, I hope that integrated STEM teaching will be implemented in a larger scale and in a greater depth.}

In the interview, she said, "I often demanded my mentees to better implement integrated STEM teaching and expected our teaching should achieve more ideal effects... However, many of the real teaching effects did not meet my expectations".

During the year as a mentor, Sunjie communicated with and interviewed many principals, experts, and STEM teachers. After one year as a mentor, Sunjie told us that she was often excited about the changes in students, teachers, and other stakeholders:

\section{I find that more and more students are attracted by integrated STEM teaching... Researchers and par- ents pay more attention to STEM education... And, more and more schools get really involved in the STEM curriculum reforms... All these changes are very exciting.}

These changes in stakeholders showed the potential of STEM education in China, which made Sunjie particularly excited. As she told us, "Although STEM education started late in China, it shows a strong momentum of development and strong vitality. I am particularly excited about that". Furthermore, these changes helped Sunjie realize the meaning of her professional identity as a mentor, that is, a mentor should contribute to these successful education changes.

After deeply realizing the values of STEM education, Sunjie believed that such education was particularly needed because innovation is strongly promoted across the country. She had strong confidence in the prospects of STEM education in China. However, as a mentor, 
Sunjie had a deeper understanding of problems in the STEM curriculum reforms. She expressed some concerns to us in a conversation. Sunjie was a little unsatisfied with the traditional culture of conformism and examinationoriented teaching because they could make many people reluctant to change and, thus, slow STEM education reform. Most importantly, she emphasized that teachers were at the heart of the reforms and spent too much effort on integrated STEM teaching while often lacking support and attention:

Teachers are often said to be emotional laborers. I want to add that STEM teachers are like crazy people because they have to put their emotions into studying and teaching regardless of the cost. Their efforts are out of proportion to what they get... They are silent and courageous implementers of reforms, while they haven't gotten enough care and support they need... I hope this unsatisfactory situation can be improved.

All these concerns helped Sunjie realize the responsibility of the professional identity as a mentor. As she stated, a mentor should help more explorers go out of "the shell".

Generally, Sunjie, as a mentor, felt excited because she saw some of the successes of the STEM curriculum reforms in China. In addition, Sunjie felt unsatisfied with the situation of STEM education because she encountered some issues and challenges with STEM education reforms. As she concluded, these were the two sides of reform. Teachers were always experiencing both positive and negative emotions in the reforms. Sunjie further stated that the mixed emotions of excitement and unsatisfaction stimulated her to be an excellent mentor and make more contributions to the development of STEM education in her district.

\section{Discussion}

The findings reveal that the development of teacher emotions and the formation and transformation of teacher professional identities are not simple and linear processes, but can be understood as multi-level and open systems with interactions (e.g., principals, colleagues, students, and experts), interrelationships (e.g., the personal characteristics, teaching philosophy, ideal concept of education, school climate, education policies of STEM education, successes and challenges of STEM education reform in China, realities of STEM education in China, traditional Chinese classroom culture, and Chinese socio-cultural backgrounds), and interdependencies of elements (e.g., the similarities and differences in views of STEM education and STEM curriculum reforms at different stages). This finding is aligned with prior studies on teacher professional identities (Leigh, 2019; Li \& Craig, 2019; Schutz et al., 2018) or emotions (Chen, 2016; Tsang \& Kwong, 2017; Zhang, 2020), which emphasize the complexities of teacher professional identities or emotions. In addition, this current study further justified the close and strong relationship between teacher professional identities and emotions by focusing on a STEM teacher's professional identities and emotions in the context of STEM education reforms.

Teacher emotion is an indispensable component of the construction and development of teachers' professional identities. First, in line with previous studies (Timoštšuk \& Ugaste, 2012; van Veen \& Sleegers, 2009), this current study found that positive emotions helped reinforce Sunjie's professional identities. For instance, Sunjie especially emphasized that her interest in and enthusiasm for integrated STEM teaching were the driving forces that kept her committed to her professional aspirations. These positive emotions motivated her to pursue professional identities at different stages. Furthermore, she recognized that she could not keep going without the support of these positive emotions. Second, this current study found that negative emotions did not always threaten a teacher's professional identities, which is different from van Veen and Sleegers's (2009) statement. If a teacher like Sunjie was able to appropriately treat and regulate negative emotions, then negative emotions may speed up the transformation and formation of that teacher's professional identities. For instance, Sunjie claimed that motivation usually comes from pressure. As she stated, her worry about the integrated STEM teaching effect pushed her to work harder to be a better explorer. In addition, Sunjie's un-satisfaction with STEM education inspired her to do as much as she could to take ownership of the STEM curriculum reforms and make more contributions to the development of STEM education in her district. Her un-satisfaction further helped her become a better mentor. In fact, it is normal for teachers, especially STEM teachers, to experience negative emotions in identity construction. Crucially, as Sunjie argued, teachers must have the capacity to regulate these negative emotions. For example, they can correctly consider pressure as a source of motivation. Because of the high demands of STEM education reform, STEM teachers must realize that opportunities and challenges have always co-existed and that negative and positive emotions are intertwined. Therefore, STEM teachers must learn to deal with the relationship between negative and positive emotions and to allow positive emotions to dominate their professional lives.

Because Sunjie emphasized the importance of the capacity to regulate emotions, it is meaningful to find out how she used internal strategies to eliminate negative 
emotions and generate positive emotions. According to Taxer and Gross's (2018) and Gross's (2015) classification, Sunjie's strategies included mainly situation modification, attentional deployment, and cognitive change. For instance, Sunjie practiced her integrated STEM teaching in different ways. This type of situation modification helped her avoid the undesirable situations that occurred in her first teaching. Additionally, Sunjie improved her emotions by focusing on the alignment between what she was doing and what the education reform policies encouraged. This attentional deployment helped her walk out of the frustrating classroom situations and increased her enthusiasm. As for cognitive change, Sunjie learned to treat her unsuccessful teaching as something from which she could learn rather than something that made her sad. These useful and effective strategies of emotion regulation can be recommended for STEM teachers who are struggling under the STEM education reforms. However, the effectiveness of these regulation strategies often depends on specific classroom situations (Taxer \& Gross, 2018). Therefore, how STEM teachers regulate their emotions in specific STEM classroom situations still needs to be investigated in the future.

Because positive emotions are of great help in reinforcing STEM teachers' professional identities, it is meaningful to find the sources. El Nagdi et al. (2018) emphasized that consistency or alignment between teachers' teaching philosophy and understanding of STEM is essential for developing professional identities. In this current study, we found that consistency or alignment played a significant role in the generation of Sunjie's positive emotions and in the emotional construction of Sunjie's professional identities. For instance, Sunjie stated that her interest in STEM education came from such a consistency. Also, she considered integrated STEM teaching to be an effective teaching model about which she was enthusiastic. We may conclude that when STEM teachers have a deeper understanding of STEM education and its values, as well as the connections between the ideas of STEM education and their teaching philosophy, they are more likely to be interested in and willing to try integrated STEM teaching. In other words, one of the prerequisites for teachers to generate sustainable positive emotions is for them to realize the values of STEM education. In this sense, teachers' beliefs in STEM education may influence their emotions as internal sources.

Meanwhile, it was found that Sunjie had a high level of self-motivation (i.e., Sunjie's ability to motivate herself to perform difficult and challenging tasks), which is an essential internal source of her positive emotions. This current study confirmed prior findings that teachers with high self-motivation are more likely to up-regulate positive emotions (e.g., Kamila et al., 2014). For instance, although Sunjie knew that she would encounter numerous challenges and difficulties, she motivated herself to make more efforts to be a great STEM teacher and stay enthusiastic to overcome challenges. Also, as an explorer, Sunjie stated that she always motivated herself to stay active in doing what she loved and wanted to do. Selfmotivation helped her remain enthusiastic. Therefore, self-motivation might be regarded as one of the most significant determinants of teachers' positive emotions.

In addition to the aforementioned internal sources (e.g., emotion regulation strategies, personal beliefs in STEM education, self-motivation, etc.), two main external sources of Sunjie's positive emotions are scrutinized. First, as long as related educational policies confirmed Sunjie's belief that her exploration of integrated STEM teaching was valuable, then this belief further increased her enthusiasm. This indicates the important role of educational policies (including national reform policies and local supporting policies) in influencing STEM teachers' emotions. Second, school climate (i.e., colleagues' encouragement and school leaders' and experts' recognition) supported Sunjie's quest for a better explorer and mentor. For instance, before Sunjie first integrated STEM teaching, her colleagues' positive comments made her more enthusiastic about what she was interested in. Additionally, when Sunjie's and her mentees' teaching implementations were recognized by many leaders, experts, and researchers, Sunjie felt very excited. Therefore, these two external sources contributed to Sunjie's self-realization in the STEM curriculum reforms and helped her generate positive emotions. Because of this, related STEM educational policies could be created for the development of STEM education, and a supportive school climate for STEM education reforms could be cultured.

This current study extends Bybee's (2010) conceptualization by developing a conceptual framework for the relationships among STEM teacher emotions, STEM teacher professional identities, and successful STEM education changes under the STEM education reform (see Fig. 1). Our findings provide initial empirical evidence regarding the relationships within the conceptual framework. Actually, the relationships within the conceptual framework not only further confirm Bybee's (2010) model that the process of creating new or multiple professional identities would influence and be influenced by the process of education changes, but also indicate that teacher emotions would influence and be influenced by the process of creating new or multiple professional identities. These three processes (i.e., the process of education changes, the process of creating new or multiple professional identities, and the generation process of teacher emotions) are intertwined and developed 
with each other. In the background of STEM education reforms, STEM teachers' negative emotions, caused by STEM education reforms, is an urgent issue. Meanwhile, all stakeholders must face and solve this issue from the development of STEM education. We hope the conceptual framework will provide a perspective for developing a solution to this issue.

It is necessary to mention that our participant, Sunjie, is female, while female is significantly underrepresented in STEM fields (Cotner et al., 2020; Dancy et al., 2020; Kaleva et al., 2019; Kricorian et al., 2020; Rainey et al., 2019). After experiencing a number of challenges and difficulties, Sunjie was still positive and had her professional dreams. Sunjie's journey demonstrates her courage, motivation, and persistence in STEM fields as a female STEM teacher. This is aligned with Chinese gender norms, that is, women are capable of holding up half the world. Female STEM teachers' emotions and identities may be influenced gender norms. However, such underlying influencing mechanisms need further investigations.

\section{Conclusion and implications}

Employing a narrative inquiry approach, this study provides a series of vivid and dynamic pictures of a STEM teacher's emotions and professional identities against the background of STEM education reform in China from a 3-year longitudinal perspective. Positive and negative emotions were intertwined in Sunjie's experiences as a learner, explorer, and mentor. These emotions helped construct and shape Sunjie's professional identities and encouraged her to be the best STEM teacher that she could be. This study contributes to the theoretical and practical understanding of teachers' emotional change and constructions of professional identities under STEM education reforms, which have been studied in few Asian settings.

For the theoretical aspect, our findings extend Bybee's (2010) conceptualization by indicating that the three processes (i.e., the process of education changes, the process of creating new or multiple professional identities, and the generation process of teacher emotions) are intertwined and developed with each other under the STEM education reform. Particularly, we argue that negative emotions may speed up the transformation and formation of teacher professional identities, which reinforces Veen and Sleegers's (2009) theoretical perspective. Furthermore, although the complexities of teacher emotions and professional identities have been emphasized in prior studies (Chen, 2016; Leigh, 2019; Li \& Craig, 2019; Schutz et al., 2018; Tsang \& Kwong, 2017; Zhang, 2020), our findings further confirm these complexities in the context of STEM teacher education. Meanwhile, the current study supports the idea that the development of
STEM teacher emotions and the formation and transformation of STEM teacher professional identities can be understood as a multi-level and open system. During this process, various internal/personal and external (including social, cultural, and contextual) factors are interwoven to create strong effects on STEM teachers' emotional experiences and to provoke both positive and negative emotions. These mixed emotions either strengthen or weaken STEM teacher professional identities. Figure 3 summarizes the research findings and theoretical contributions within the conceptual framework.

For the practical aspect, this study would help promote STEM education reforms and STEM teacher development as follows.

Hargreaves (1997) argued that "if educational reformers ignore the emotional dimensions of educational change, emotions and feelings will only re-enter the change process by the back door" (p. 108-109). Also, James and Connolly (2000) claimed that "responses to change may be influenced by very powerful non-rational emotional forces" (p. 146). This study further called for more attention on teacher emotions under STEM education reforms. The main body in the education and curriculum reforms is people, among whom the most important ones are teachers (Huang \& Liu, 2020). A teacher should be treated as a person with rich emotional experiences and inner worlds instead of as a machine for implementing reform measures. Therefore, we suggest that policymakers, administrators, researchers, and other stakeholders pay more attention to teachers' various emotional experiences in the process of education changes, especially negative emotions, and help teachers reduce the negative effects of negative emotions. In China, many STEM teachers are science or math teachers before they become involved in STEM education and curriculum reforms. This implies that they must transform their professional identities and make efforts to meet the fundamental requirements of STEM education and curriculum reforms. Because STEM teaching is challenging, teachers are more likely to experience negative emotions in the identity transformation. Relevant stakeholders can widen the emotional expression channel for teachers (e.g., create a supportive school climate and a culture of trust, provide teachers with psychological counseling, and guide teachers in releasing their emotions naturally), help teachers practice the strategies of emotion regulation, analyze the emotions behind the social, cultural, moral, contextual, and professional factors, provide a variety of supports for STEM teachers (e.g., create policies to help eliminate unfavorable factors of STEM teachers' positive emotions), and help teachers better construct their professional identities. When STEM teachers are released from tired emotional labor, they will play a significant 


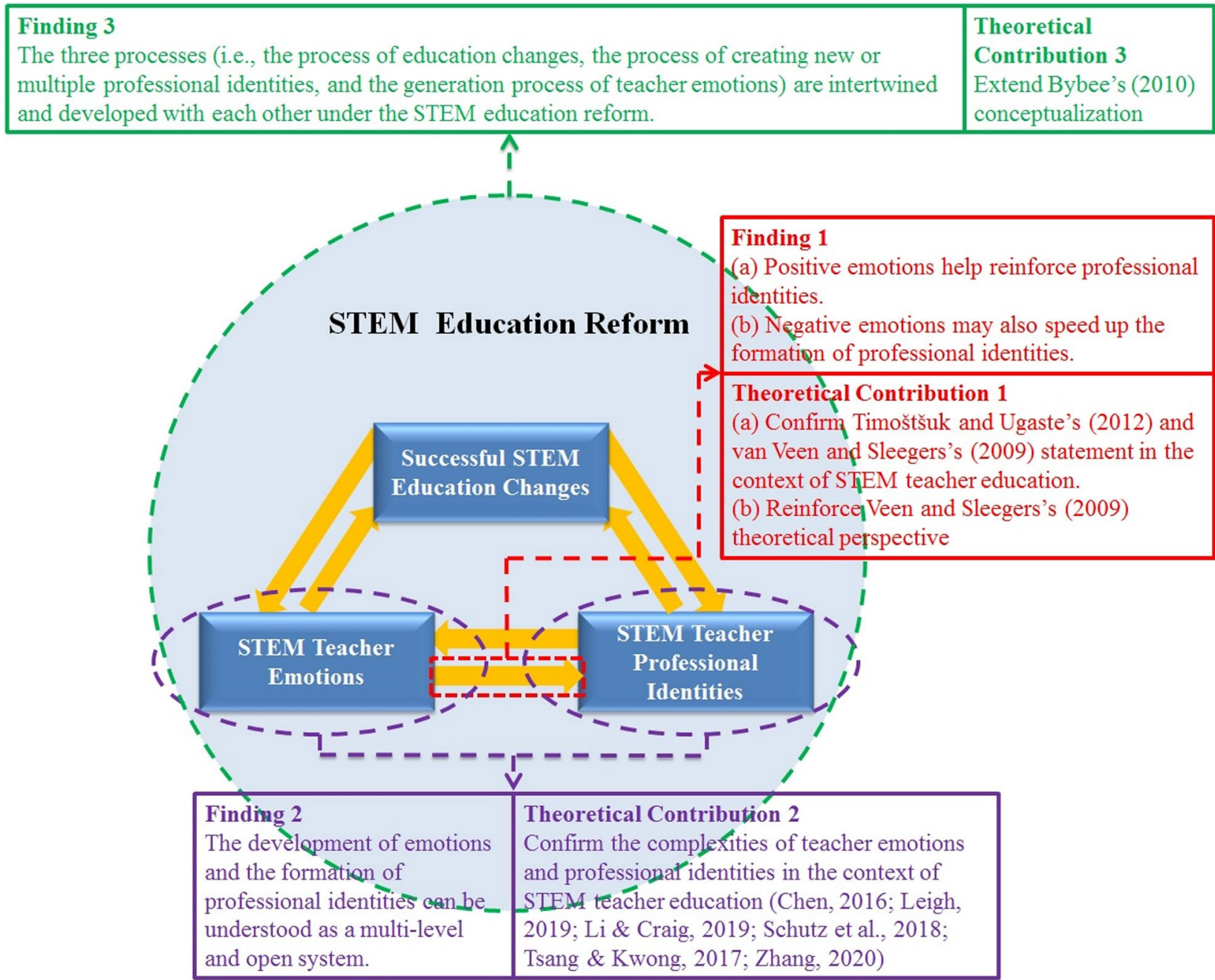

Fig. 3 A conclusion of the research findings and theoretical contributions

role as supporters in advocating for and implementing STEM reform initiatives.

Teacher emotion is a significant aspect of STEM teacher professional development. Teacher educators can help STEM teachers realize the roles of emotion in identity construction by analyzing the cases involving dealing with various emotions generated in the STEM education reforms. Furthermore, teacher educators can encourage STEM teachers to take action to contribute to the development of STEM education under the changing education climate. When more STEM teachers are likely to transform and shape professional identities with more positive emotions, the subtle positive relationship between teacher professional development and STEM education development could be better built in the future.

Without minimizing the limitations of this study, it is important to recognize that understanding a STEM teacher's emotions and professional identities in the context of Shenzhen, one of the most open and developed cities in China, is illuminating, as the participant is at the forefront of the STEM education and curriculum reforms. Furthermore, it is necessary to recognize that STEM education reforms have not been fully implemented in most rural areas of China. Future research is needed to understand STEM teachers' emotions and professional identities in these rural areas, where related local support is weak. Also, more work is needed to understand whether and how these reported changes in emotions and professional identities of a STEM teacher influence their instructional behaviors, qualities of integrated STEM teaching, and students' learning outcomes under the STEM curriculum reforms. Besides, we recommend that more attention can be paid to the underrepresented groups (e.g., female STEM teachers). In addition to their professional identities, their personal 
identities and emotions as women in STEM fields need to be explored as well. It is also meaningful to investigate how underlying gender norms affect their emotions and identities. Last but not least, prior studies found that teacher emotions and teachers' display of emotions may be affected by cultural factors (Hayik \& Weiner-Levy, 2019; Mendzheritskaya \& Hansen, 2019). Further studies are needed to explore how STEM teacher emotions are potentially impacted by Asian educational culture (e.g., rote learning, teacher-directed, exam-oriented, etc.) and how STEM teachers' display of emotions are potentially impacted by Confucian culture (e.g., require individuals to be implicative, etc.).

\section{Appendix}

Some interview questions used:

Section 1 Overall 3-year experiences related to STEM education.

1. Could you please review your overall 3-year experience related to STEM education?

\section{Section 2 Different emotions at different stages}

2. What kinds of emotions did you experience when you learned STEM education in the US (from September 2016 to March 2017)? Would you please share with us the emotional journey when you were a learner?

3. What kinds of emotions did you experience when you implemented integrated STEM teaching in your school (from March 2017 to September 2018)? Would you please share with us the emotional journey when you were a teacher?

4. What kinds of emotions did you experience after you became a mentor (from September 2018 to September 2019)? Would you please share with us the emotional journey when you were a mentor?

Section 3 Formations and transformations of professional identities.

5. Why did you choose to learn STEM education in the US? Meanwhile, you experienced both positive and negative emotions when you were a learner. Did these emotions influence your professional identity as a learner? Why?

6. Why did you choose to implement integrated STEM teaching after you came back to your hometown? Meanwhile, you experienced both positive and negative emotions when you were an explorer. Did these emotions influence your professional identity as an explorer? Why?

7. Why did you want to be a mentor? Meanwhile, you experienced both positive and negative emotions when you were a mentor. Did these emotions influence your professional identity as a mentor? Why?

\section{Section 4 Chinese STEM education reforms.}

8. What do you think of Chinese STEM education and STEM education reforms?

\section{Acknowledgements}

The authors would like to express their sincere gratitude to the seven anonymous reviewers and the editors for their thoughtful, helpful and critical comments on earlier versions of this article.

\section{Authors' contributions}

$\mathrm{HJ}$ and KW conceptualized the study. HJ wrote the draft. KW and XW contributed to the manuscript through critical reviews. HJ and KW revised the manuscript. HJ, KW and XW finalized the manuscript. KW edited the manuscript. XW monitored the project and provided adequate supervision. All authors contributed with data collection, coding, analyses and interpretation. All authors read and approved the final manuscript.

\section{Funding}

This work is supported by (1) the Peak Discipline Construction Project of Education at East China Normal University, Shanghai, People's Republic of China and (2) the Academic Innovation Capacity Enhancement Project for Excellent Doctoral Students at East China Normal University, Shanghai, People's Republic of China.

\section{Availability of data and materials}

The datasets generated and analyzed during the current study are not publicly available due to the identifiable nature of the data.

\section{Declarations}

\section{Competing interests}

The authors declare that they have no competing interests.

\section{Author details}

${ }^{1}$ College of Teacher Education, Faculty of Education, East China Normal University, Shanghai 200062, People's Republic of China. ${ }^{2}$ Department of Teacher Education, Nicholls State University, Thibodaux, LA 70310, USA. ${ }^{3}$ Guangzhou Tianhe District Teacher Development Center, Guangzhou 510655, Guangdong, People's Republic of China. ${ }^{4}$ Shenzhen Experimental School, Shenzhen 518000, Guangdong, People's Republic of China.

Received: 11 February 2021 Accepted: 11 August 2021

Published online: 17 August 2021

\section{References}

Atmaca, C., Rzaolgu, F., Turkdogan, T., \& Yayli, D. (2020). An emotion focused approach in predicting teacher burnout and job satisfaction. Teaching and Teacher Education, 90, 1-13. https://doi.org/10.1016/j.tate.2020. 103025

Becker, E. S., Goetz, T., Morger, V., \& Ranellucci, J. (2014). The importance of teachers' emotions and instructional behavior for their students' emotions-An experience sampling analysis. Teaching and Teacher Education, 43, 15-26. https://doi.org/10.1016/j.tate.2014.05.002 
Bodenheimer, G., \& Shuster, S. M. (2020). Emotional labour, teaching and burnout: Investigating complex relationships. Educational Research, 62(1), 63-76. https://doi.org/10.1080/00131881.2019.1705868

Bruner, J. (1987). Life as narrative. Social Research, 54(1), 11-32.

Buric, I., \& Frenzel, A. C. (2019). Teacher anger: New empirical insights using a multi-method approach. Teaching and Teacher Education, 86, 1-11. https://doi.org/10.1016/j.tate.2019.102895

Buric, l., Sliskovic, A., \& Penezic, Z. (2019). Understanding teacher well-being: A cross-lagged analysis of burnout, negative student-related emotions, psychopathological symptoms, and resilience. Educational Psychology, 39(9), 1136-1155. https://doi.org/10.1080/01443410.2019.1577952

Bybee, R. W. (2010). Advancing STEM education: A 2020 vision. Technology and Engineering Teacher, 70(1), 30-35.

Chen, J. (2016). Understanding teacher emotions: The development of a teacher emotion inventory. Teaching and Teacher Education, 55, 68-77. https://doi.org/10.1016/j.tate.2016.01.001

Chen, J. (2019). Research review on teacher emotion in Asia between 1988 and 2017: Research topics, research types, and research methods. Frontiers in Psychology, 10, 1-16. https://doi.org/10.3389/fpsyg.2019.01628

Chen, J. (2020). Development and validation of the Principal Emotion Inventory: A mixed-methods approach. Educational Management Administration \& Leadership. https://doi.org/10.1177/1741143220919764

Clandinin, J., \& Connelly, M. (2000). Narrative inquiry: Experience and story in qualitative research. Jossey-Bass.

Connelly, M., \& Clandinin, J. (1990). Stories of experience and narrative inquiry. Educational Researcher, 19(5), 2-14. https://doi.org/10.3102/0013189X01 9005002

Connelly, M., \& Clandinin, J. (1999). Shaping a professional identity: Stories of education practice. Althouse Press.

Cotner, S., Jeno, L. M., Walker, J. D., Jørgensen, C., \& Vandvik, V. (2020). Gender gaps in the performance of Norwegian biology students: The roles of test anxiety and science confidence. International Journal of STEM Education, 7, 55. https://doi.org/10.1186/s40594-020-00252-1

Craig, C. (2007). Story constellations: A narrative approach to contextualizing teachers' knowledge of school reform. Teaching and Teacher Education, 23, 173-188. https://doi.org/10.1016/j.tate.2006.04.014

Craig, C. (2019). From starting stories to staying stories to leaving stories: The experiences of an urban English as a second language teacher. Research Papers in Education, 34(3), 298-329. https://doi.org/10.1080/02671522. 2018.1424929

Dancy, M., Rainey, K., Stearns, E., Mickelson, R., \& Moller, S. (2020). Undergraduates' awareness of White and male privilege in STEM. International Journal of STEM Education, 7, 52. https://doi.org/10.1186/s40594-020-00250-3

De Costa, P. I., Li, W., \& Rawal, H. (2019). Language teacher emotions. In M. Peters (Ed.), Encyclopedia of teacher education. Springer. https://doi.org/10. 1007/978-981-13-1179-6_262-1

Denzin, N. K. (1989). The research act: A theoretical introduction to sociological methods (3rd ed.). Prentice Hall.

Dong, Y., Wang, J., Yang, Y., \& Kurup, P. M. (2020). Understanding intrinsic challenges to STEM instructional practices for Chinese teachers based on their beliefs and knowledge base. International Journal of STEM Education, 7, 47. https://doi.org/10.1186/s40594-020-00245-0

El Nagdi, M., Leammukda, F., \& Roehrig, G. (2018). Developing identities of STEM teachers at emerging STEM schools. International Journal of STEM Education, 5, 36. https://doi.org/10.1186/s40594-018-0136-1

El Nagdi, M., \& Roehrig, G. (2020). Identity evolution of STEM teachers in Egyptian STEM schools in a time of transition: A case study. International Journal of STEM Education, 7, 41. https://doi.org/10.1186/s40594-020-00235-2

English, L. D. (2016). STEM education K-12: Perspectives on integration. International Journal of STEM Education, 3, 3. https://doi.org/10.1186/ s40594-016-0036-1

Etikan, I., Musa, S. A., \& Alkassim, R. S. (2016). Comparison of convenience sampling and purposive sampling. American Journal of Theoretical and Applied Statistics, 5(1), 1-4. https://doi.org/10.11648/j.ajtas.20160501.11

Frenzel, A. (2014). Teacher emotions. In R. Pekrun \& L. Linnenbrink-Garcia (Eds.), International handbook of emotions in education (pp. 494-519). Routledge.

Frenzel, A. C., Fiedler, D., Marx, A. K. G., Reck, C., \& Pekrun, R. (2020). Who enjoys teaching, and when? Between- and within-person evidence on teachers' appraisal-emotion links. Frontiers in Psychology, 11, 1-14. https://doi.org/ 10.3389/fpsyg.2020.01092
Frenzel, A. C., Goetz, T., Stephens, E. J., \& Jacob, B. (2009). Antecedents and effects of teachers' emotional experiences: An integrated perspective and empirical test. In P. Schutz \& M. Zembylas (Eds.), Advances in teacher emotion research (pp. 129-151). Springer. https://doi.org/10.1007/ 978-1-4419-0564-2_7

Frenzel, A. C., Kurz, B. B., Pekrun, R., Goetz, T., \& Lüdtke, O. (2018). Emotion transmission in the classroom revisited: A reciprocal effects model of teacher and student enjoyment. Journal of Educational Psychology, 110(5), 628-639. https://doi.org/10.1037/edu0000228

Golombek, P., \& Doran, M. (2014). Unifying cognition, emotion, and activity in language teacher professional development. Teaching and Teacher Education, 39, 102-111. https://doi.org/10.1016/j.tate.2014.01.002

Gross, J. J. (2015). Emotion regulation: Current status and future prospects. Psychological Inquiry, 26(1), 1-26.

Hagenauer, G., Hascher, T., \& Volet, S. E. (2015). Teacher emotions in the classroom: Associations with students' engagement, classroom discipline and the interpersonal teacher-student relationship. European Journal of Psychology of Education, 30(4), 385-403. https://doi.org/10.1007/ s10212-015-0250-0

Hallström, J., \& Schönborn, K. J. (2019). Models and modelling for authentic STEM education: Reinforcing the argument. International Journal of STEM Education, 6, 22. https://doi.org/10.1186/s40594-019-0178-z

Hanna, F., Oostdam, R., Severiens, S. E., \& Zijlstra, B. J. H. (2020). Assessing the professional identity of primary student teachers: Design and validation of the Teacher Identity Measurement Scale. Studies in Educational Evaluation, 64, 100822. https://doi.org/10.1016/j.stueduc.2019.100822

Hargreaves, A. (1997). Rethinking educational change with heart and mind. The Association for Supervision and Curriculum Development Yearbook.

Hargreaves, A. (1998). The emotional politics of teaching and teacher development: With implications for educational leadership. International Journal of Leadership in Education, 1(4), 315-336. https://doi.org/10.1080/13603 12980010401

Hayik, R., \& Weiner-Levy, N. (2019). Prospective Arab teachers' emotions as mirrors to their identities and culture. Teaching and Teacher Education, 85, 36-44. https://doi.org/10.1016/j.tate.2019.05.006

Hong, J., \& Cross Francis, D. (2020). Unpacking complex phenomena through qualitative inquiry: The case of teacher identity research. Educational Psychologist, 55(4), 208-219. https://doi.org/10.1080/00461520.2020. 1783265

Huang, Y., \& Liu, H. (2020). Teachers' emotion in the new college entrance examination reform: Narrative inquiry based on emotion geographies. Global Education, 49(4), 85-105.

James, C. R., \& Connolly, U. (2000). Effective change in schools. Routledge Falmer.

Kaleva, S., Pursiainen, J., Hakola, M., Rusanen, J., \& Muukkonen, H. (2019). Students' reasons for STEM choices and the relationship of mathematics choice to university admission. International Journal of STEM Education, 6, 43. https://doi.org/10.1186/s40594-019-0196-x

Kamila, W., Nicola, B., Lis, F., Stefan, E., \& Kenji, H. (2014). Live to work or love to work: Work craving and work engagement. PLOS ONE, 9(10), 1-7. https:// doi.org/10.1371/journal.pone.0106379

Kazén, M., Kuhl, J., \& Leicht, E. M. (2015). When the going gets tough...: Selfmotivation is associated with invigoration and fun. Psychological Research Psychologische Forschung, 79(6), 1064-1076. https://doi.org/10.1007/ s00426-014-0631-z

Kelley, T. R., \& Knowles, J. G. (2016). A conceptual framework for integrated STEM education. International Journal of STEM Education, 3, 11. https://doi. org/10.1186/s40594-016-0046-z

Kricorian, K., Seu, M., Lopez, D., Ureta, E., \& Equils, O. (2020). Factors influencing participation of underrepresented students in STEM fields: Matched mentors and mindsets. International Journal of STEM Education, 7, 16. https:// doi.org/10.1186/s40594-020-00219-2

Lee, C. K., Huang, X. H., Law, H. F., \& Wang, M. H. (2013). Professional identities and emotions of teachers in the context of curriculum reform: A Chinese perspective. Asia-Pacific Journal of Teacher Education, 41(3), 271-287. https://doi.org/10.1080/1359866X.2013.809052s

Leigh, L. (2019). "Of course I have changed!": A narrative inquiry of foreign teachers' professional identities in Shenzhen, China. Teaching and Teacher Education, 86, 1-11. https://doi.org/10.1016/j.tate.2019.102905

Leung, A. (2020). Boundary crossing pedagogy in STEM education. International Journal of STEM Education, 7, 15. https://doi.org/10.1186/ s40594-020-00212-9 
Li, J., \& Craig, C. J. (2019). A narrative inquiry into a rural teacher's emotions and identities in China: Through a teacher knowledge community lens. Teachers and Teaching, 25(8), 918-936. https://doi.org/10.1080/13540602. 2019.1652159

Li, Y. (2018). Journal for STEM education research—Promoting the development of interdisciplinary research in STEM education. Journal for STEM Education Research, 1(1-2), 1-6. https://doi.org/10.1007/ s41979-018-0009-Z

Li, Y. (2020). Six years of development in promoting identity formation of STEM education as a distinct field. International Journal of STEM Education, 7, 59. https://doi.org/10.1186/s40594-020-00257-w

Li, Y., \& Anderson, J. (2020). STEM integration: Diverse approaches to meet diverse needs. In J. Anderson \& Y. Li (Eds.), Integrated approaches to STEM Education: An international perspective. Springer. https://doi.org/10.1007/ 978-3-030-52229-2_2

Li, Y., Schoenfeld, A. H., diSessa, A. A., Graesser, A. C., Benson, L. C., English, L. D., \& Duschl, R. A. (2019). On thinking and STEM education. Journal for STEM Education Research, 2(1), 1-13. https://doi.org/10.1007/ s41979-019-00014-X

Li, Y., Wang, K., Xiao, Y., \& Froyd, J. E. (2020a). Research and trends in STEM education: A systematic review of journal publications. International Journal of STEM Education, 7, 11. https://doi.org/10.1186/s40594-020-00207-6

Li, Y., Wang, K., Xiao, Y., Froyd, J. E., \& Nite, S. B. (2020b). Research and trends in STEM education: A systematic analysis of publicly funded projects. International Journal of STEM Education, 7, 17. https://doi.org/10.1186/ s40594-020-00213-8

Lian, Y., Tsang, K.-K., \& Zhang, Y. (2021). The construction and sustainability of teachers' positive emotions toward STEM educational work. Sustainability, 13(11), 5769. https://doi.org/10.3390/su13115769

Macqueen, S., \& Patterson, C. (2020). Reflexivity in a longitudinal narrative inquiry: Pursuit of clarity of interpretations. International Journal of Research \& Method in Education. https://doi.org/10.1080/1743727X.2020. 1724279

Margot, K. C., \& Kettler, T. (2019). Teachers' perception of STEM integration and education: A systematic literature review. International Journal of STEM Education, 6, 2. https://doi.org/10.1186/s40594-018-0151-2

Mendzheritskaya, J., \& Hansen, M. (2019). Are lecturers who show emotions perceived as understanding? How culture and teacher's display of emotion are related to students'judgments about a teacher's personality. Studies in Higher Education, 44(10), 1793-1802. https://doi.org/10.1080/ 03075079.2019 .1665332

Ministry of Education of the People's Republic of China. (2017). New standards of the primary school science curriculum. Beijing Normal University Press.

Nalipay, M. J. N., Mordeno, I. G., Semilla, J. B., \& Frondozo, C. E. (2019). Implicit beliefs about teaching ability, teacher emotions, and teaching satisfaction. The Asia-Pacific Education Researcher, 28, 313-325. https://doi.org/10. 1007/s40299-019-00467-z

Nichols, S., Schutz, P. A., Rodgers, K., \& Bilica, K. (2017). Early career teachers' emotion and emerging teacher identities. Teachers and Teaching, 23(4), 406-421. https://doi.org/10.1080/13540602.2016.1211099

Parr, A., Gladstone, J., Rosenzweig, E., \& Wang, M. T. (2021). Why do I teach? A mixed-methods study of in-service teachers' motivations, autonomysupportive instruction, and emotions. Teaching and Teacher Education, 98, 1-13. https://doi.org/10.1016/j.tate.2020.103228

Peng, M., \& Zhu, D. (2020). Chinese teachers' perception of STEM education: Based on the qualitative analysis of 52 STEM teachers by NVivo11 software. Research in Educational Development, 40(10), 60-65.

Polkinghorne, D. E. (1995). Narrative configuration in qualitative analysis. International Journal of Qualitative Studies in Education, 8(1), 5-23. https:// doi.org/10.1080/0951839950080103

Prabjandee, D. (2020). Narratives of learning to become English teachers in Thailand: Developing identity through a teacher education program. Teacher Development, 24(1), 71-87. https://doi.org/10.1080/13664530. 2019.1699155

Rainey, K., Dancy, M., Mickelson, R., Stearns, E., \& Moller, S. (2019). A descriptive study of race and gender differences in how instructional style and perceived professor care influence decisions to major in STEM. International Journal of STEM Education, 6, 6. https://doi.org/10.1186/ s40594-019-0159-2

Richardson, P. W., \& Watt, H. M. G. (2018). Teacher professional identity and career motivation: A lifespan perspective. In P. Schutz, J. Hong, \& D. C.
Francis (Eds.), Research on teacher identity (pp. 37-48). Springer. https:// doi.org/10.1007/978-3-319-93836-3_4

Schutz, P. A., Francis, D. C., \& Hong, J. (2018). Research on teacher identity: Introduction to mapping challenges and innovations. In P. Schutz, J. Hong, \& D. C. Francis (Eds.), Research on teacher identity (pp. 3-9). Springer. https://doi.org/10.1007/978-3-319-93836-3_1

Schutz, P. A., Hong, J. Y., Cross, D. I., \& Osbon, J. N. (2006). Reflections on investigating emotion in educational activity settings. Educational Psychology Review, 18(4), 343-360. https://doi.org/10.1007/s10648-006-9030-3

Schutz, P. A., \& Pekrun, R. (2007). Emotion in education. Academic Press. https:// doi.org/10.1016/B978-0-12-372545-5.X5000-X

Schutz, P. A., \& Zembylas, M. (2009). Advances in teacher emotion research. Springer. https://doi.org/10.1007/978-1-4419-0564-2

Slavit, D., Nelson, T., \& Lesseig, K. (2016). The teachers' role in developing, opening, and nurturing an inclusive STEM-focused school. International Journal of STEM Education, 3, 7. https://doi.org/10.1186/s40594-016-0040-5

Stehle, S. M., \& Peters-Burton, E. E. (2019). Developing student 21st Century skills in selected exemplary inclusive STEM high schools. International Journal of STEM Education, 6, 39. https://doi.org/10.1186/ s40594-019-0192-1

Sutton, R. E., \& Wheatley, K. F. (2003). Teachers'emotions and teaching: A review of the literature and directions for future research. Educational Psychology Review, 15(4), 327-358. https://doi.org/10.1023/A:1026131715856

Taxer, J. L., \& Gross, J. J. (2018). Emotion regulation in teachers: The "why" and "how." Teaching and Teacher Education, 74, 180-189. https://doi.org/10. 1016/j.tate.2018.05.008

The Chinese Academy of Educational Sciences. (2017). China STEM education white paper. The Author.

Timoštšuk, I., \& Ugaste, A. (2012). The role of emotions in student teachers' professional identity. European Journal of Teacher Education, 35(4), 421-433. https://doi.org/10.1080/02619768.2012.662637

Torres, A. S. (2021). Emotions, identity, and commitment among early leavers in the United States of America. Teachers and Teaching. https://doi.org/10. 1080/13540602.2021.1889494

Tsang, K. K., \& Kwong, T. L. (2017). Teachers' emotions in the context of education reform: Labor process theory and social constructionism. British Journal of Sociology of Education, 38(6), 841-855. https://doi.org/10.1080/ 01425692.2016 .1182007

Turner, J. H. (2009). The sociology of emotions: Basic theoretical arguments Emotion Review, 1(4), 340-354. https://doi.org/10.1177/1754073909 338305

Uitto, M., Jokikokko, K., \& Estola, E. (2015). Virtual special issue on teachers and emotions in Teaching and teacher education (TATE) in 1985-2014. Teaching and Teacher Education, 50, 124-135. https://doi.org/10.1016/j. tate.2015.05.008

Vähäsantanen, K. (2015). Professional agency in the stream of change: Understanding educational change and teachers' professional identities. Teaching and Teacher Education, 47, 1-12. https://doi.org/10.1016/j.tate. 2014.11.006

Vähäsantanen, K., \& Hämäläinen, R. (2019). Professional identity in relation to vocational teachers' work: An identity-centred approach to professional development. Learning: Research and Practice, 5(1), 48-66. https://doi.org/ 10.1080/23735082.2018.1487573

van Veen, K. (2008). Analyzing teachers' working conditions from the perspective of teachers as professionals. In J. Ax \& P. Ponte (Eds.), The profession of teacher in Dutch educational praxis (pp. 91-112). Sense Publishers. https:// doi.org/10.1163/9789087904562_006

van Veen, K., \& Sleegers, P. (2009). Teachers' emotions in a context of reforms: To a deeper understanding of teachers and reforms. In P. Schutz \& M. Zembylas (Eds.), Advances in teacher emotion research (pp. 233-251). Springer. https://doi.org/10.1007/978-1-4419-0564-2_12

Wahono, B., Lin, P.-L., \& Chang, C.-Y. (2020). Evidence of STEM enactment effectiveness in Asian student learning outcomes. International Journal of STEM Education, 7, 36. https://doi.org/10.1186/s40594-020-00236-1

Wang, K., Wang, X., Li, Y., \& Rugh, M. S. (2018). A framework for integrating the history of mathematics into teaching in Shanghai. Educational Studies in Mathematics, 98, 135-155. https://doi.org/10.1007/s10649-018-9811-x

Wang, X., Qi, C., \&Wang, K. (2017). A categorization model for educational values of the history of mathematics. Science \& Education, 26, 1029-1052. https://doi.org/10.1007/s11191-017-9937-8 
Watson, C. (2006). Narratives of practice and the construction of identity in teaching. Teachers and Teaching, 12(5), 509-526. https://doi.org/10.1080/ 13540600600832213

Yata, C., Ohtani, T., \& Isobe, M. (2020). Conceptual framework of STEM based on Japanese subject principles. International Journal of STEM Education, 7, 12. https://doi.org/10.1186/s40594-020-00205-8

Yuan, R., \& Lee, I. (2016). 'I need to be strong and competent': A narrative inquiry of a student-teacher's emotions and identities in teaching practicum. Teachers and Teaching, 22(7), 819-841. https://doi.org/10.1080/ 13540602.2016.1185819

Zembylas, M. (2005). Teaching with emotions: A postmodern enactment. Information Age.

Zhang, X., \& Sun, H. (2018). The study of teachers' negative emotions under the new curriculum reform. Proceedings of 3rd International Conference on Education Research and Reform (pp. 339-342). Singapore Management and Sports Science Institute.

Zhang, L., Yu, S., \& Jiang, L. (2020). Chinese preschool teachers' emotional labor and regulation strategies. Teaching and Teacher Education, 92, 1-10. https://doi.org/10.1016/j.tate.2020.103
Zhang, X. (2020). Understanding teachers' emotional trajectory: The voice of a volunteer teacher in an educationally and economically underdeveloped context. Asia-Pacific Journal of Teacher Education. https://doi.org/10.1080/ $1359866 \times .2020 .1756224$

Zhu, G. (2017). Chinese student teachers' perspectives on becoming a teacher in the practicum: Emotional and ethical dimensions of identity shaping. Journal of Education for Teaching, 43(4), 491-495. https://doi.org/10.1080/ 02607476.2017 .1341162

Zhu, G., Rice, M., Rivera, H., Mena, J., \& Want, A. V. D. (2020). 'I did not feel any passion for my teaching': A narrative inquiry of beginning teacher attrition in China. Cambridge Journal of Education. https://doi.org/10.1080/ $0305764 \times .2020 .1773763$

\section{Publisher's Note}

Springer Nature remains neutral with regard to jurisdictional claims in published maps and institutional affiliations.

\section{Submit your manuscript to a SpringerOpen ${ }^{\odot}$ journal and benefit from:}

- Convenient online submission

- Rigorous peer review

- Open access: articles freely available online

- High visibility within the field

- Retaining the copyright to your article

Submit your next manuscript at $\boldsymbol{\text { springeropen.com }}$ 